\title{
Social Welfare versus Inequality Concerns in an Incomplete Contract Experiment
}

\author{
Marco Faravelli \\ Oliver Kirchkamp \\ Helmut Rainer
}

CESIFO WORKING PAPER NO. 2933

CATEGORY 12: EMPIRICAL AND THEORETICAL METHODS

JANUARY 2010

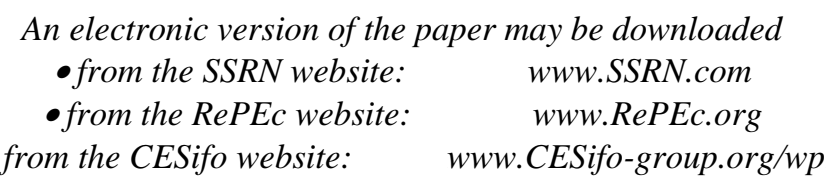




\title{
Social Welfare versus Inequality Concerns in an Incomplete Contract Experiment
}

\begin{abstract}
We study a situation where two players first choose a sharing rule, then invest into a joint production process, and then split joint benefits. We investigate how social preferences determine investments. In our experiment we find that even the materially disadvantaged player cares more for social welfare than about inequality. Behavioral preferences of disadvantaged players actually increase inequality. We also investigate when players give up an advantageous sharing rule. Power-sharing can be successful in the experiment, even when it is not in a selfish world.
\end{abstract}

JEL-Code: C91, D23, D86.

Keywords: experiments, incomplete contracts, relationship-specific investment, allocation of power, social preferences.

Marco Faravelli

School of Economics and Finance

Castlecliffe, The Scores

University of St. Andrews

UK - St Andrews KY16 9AL

mf60@st-andrews.ac.uk
Oliver Kirchkamp

Department of Economics

University of Jena

Carl-Zeiss-Strasse 3

Germany - 07743 Jena

oliver@kirchkamp.de

Helmut Rainer

Ifo Institute for Economic Research at the University of Munich

Poschingerstrasse 5

Germany-81679 Munich

rainer@ifo.de

January 22, 2010

We are grateful to Jürgen Bracht, Tim Cason, Gary Charness, Nick Feltovich, Joe Swierzbinski and Hans Hvide for helpful comments. 


\section{Introduction}

An essential characteristic of a successful partnership is that all parties involved have an incentive to make significant relationship-specific investments. However, it is not uncommon that one partner has more power than another and is therefore able to appropriate a large share of the overall benefits that accrue from the partnership. In a world with costly contracting, such power imbalances may affect resource allocations by shaping the incentives of individuals to undertake productive activities that enhance the value of partnership projects.

Power imbalances abound in many real world partnerships. The distinctive feature of sharecropping contracts in the agricultural sector is the division of product between tenants and landlords according to some predetermined share-out. The tenant's share of output has been observed to be as low as 20 percent in Southern India (Tomlinson, 1996, p. 81) or as high as 80 percent in Argentina in the 1890s (Adelman, 1994, p. 137). In a supplier-manufacturer relationship in the automotive industry, the supplier may have no comparable demanders for its parts other than the manufacturer. Consequently, the incentive for the manufacturer to appropriate quasi rents by negotiating a revised lower price at which it will accept parts from the supplier may be large (Klein et al., 1978). Power imbalances also exist in company-community partnerships in the developing world, particularly in those related to the 'fair trade' commercialization of non-timber forest products in Brazilian Amazonia (Morsello, 2006).1 Aspects of trade deals between large corporations and communities which have led to power asymmetries are premium prices and single buyers (Corry, 1993; Turner, 1995), which drastically undermine communities' negotiating power (Mayers and Vermeulen, 2002). In consequence, corporations typically appropriate larger portions of the overall benefits accruing from company-community partnerships.

The objective of this paper is to investigate experimentally whether power imbalances between trading partners discourage or encourage relationshipspecific investment when contracts are incomplete. Since the seminal work of Grossman and Hart (1986) and Hart and Moore (1990), it is well under-

\footnotetext{
${ }^{1}$ While initially the commercialization of these products was promoted primarily by non-governmental organizations, corporations such as The Body Shop or Ives Rocher now dominate the scene, having been encouraged by increased demand for environmentally and socially responsible products (Morsello and Adger, 2006)
} 
stood that there is a close connection between the allocation of power-as determined by the allocation of private control and property rights - and the incentives of partners to undertake relationship-specific investments. In this paper we build on this literature to consider how the balance of power between trading partners impacts on their investment behavior in an experimental setting. Our main contribution lies in providing new insights into the behavioral motives that enter partners' investment decisions when complete contracts are infeasible. To this end, we develop a simple model of incomple contracts based on social preferences, and use the theoretical results to guide our way of interpreting the data from our experiment.

Our experiment has the following main features. Two equally productive players simultaneously decide how much to invest into a joint production process. These investments cannot be specified in an ex-ante contract. The total monetary benefit from the production process is a Cobb-Douglas transformation of the players' respective investments. A sharing rule determines how the total monetary benefit from joint production is split between the two players. Under a symmetric or "balanced-power" partnership structure, each player is entitled to an (almost) equal share of the total monetary benefit. Under an asymmetric or "imbalanced-power" partnership structure, the power-advantaged player receives a substantially larger share of the total monetary benefit than the weak player. Throughout the experiment, we elicit not only players' own investment strategies, but also their beliefs about their partners' investment strategies.

Our experimental design allows us to address two sets of questions. The first set is: How do power imbalances between trading partners affect incentives to make relationship-specific investments? What behavioral motives do we detect when we compare partners' investment behavior under balanced and imbalanced power structures? To get at these questions, we exogenously impose both the (symmetric) balanced-power and the (asymmetric) imbalanced-power partnership structure on the players and examine their investment behavior. We show that no allocation of power induces first best investments, but some allocations are more efficient than others. In particular, since the players are equally productive, in our setup theory predicts that total investments would be lower in the presence of power imbalances. This is confirmed by our experimental evidence. However, we also observe behavioral motives entering the players' investment behavior. An 
interesting feature of our design is that it allows us to clearly disentangle inequality aversion (Fehr and Schmidt, 1999) from social-welfare concerns (Charness and Rabin, 2002). Differently from numerous other experiments in which a Pareto-improvement also decreases inequality, in our case the only way equally inequality averse players can lower payoff differences in equilibrium is by investing less efficiently. On the other hand, if players are concerned about social-welfare they will raise their investment. We find that when power is shared equally both players invest strictly more than the principle of own-payoff maximization would suggest. Also under the imbalancedpower structure, both types of players invest more than predicted by Nash equilibrium, although overinvestment is higher among strong players. This behavior is consistent with the hypothesis that individuals are concerned with social efficiency (Charness and Rabin, 2002), while it cannot be explained by inequality aversion (Fehr and Schmidt, 1999).

Having established this, we turn our attention to the following question: Under what conditions would a player which is advantaged by an asymmetric sharing rule agree to "tie her hands" and sign a contract that establishes symmetric sharing? For example, in a company-community deal in a developing country, a large corporation may have to decide whether to agree to contracts and mechanisms that allow fairer negotiations between the trade partners (Morsello, 2006). To address this issue, the following experimental procedure is adopted. Players first invest into joint production under both the symmetric and asymmetric sharing rule. Then, after having gained some experience, the players are allowed to switch from an asymmetric rule to a symmetric one. This switch requires mutual consent. Theory predicts that the disadvantaged player always has an incentive to switch to more symmetric rules. ${ }^{2}$ For the advantaged player the situation is less clear: Switching to a symmetric rule generates better incentives for total investment but also reduces this player's share of the joint profit. We analyze two situations, one in which it is individually rational for strong players to switch to a more equal structure, and one in which they should theoretically refuse to do so. Our key results are the following. Disadvantaged players almost always vote for a balanced-power partnership structure, as one would probably expect. What is more intriguing is the behavior of advantaged players, which exhibits a sub-

\footnotetext{
${ }^{2}$ This is because both total investments and weak players' shares of the benefits would increase as a result.
} 
stantial degree of heterogeneity. Surprisingly, a majority of strong players are willing to give up their strong position irrespective of whether it is individually rational or not. However, there are also participants who are disinclined to abandon power even when the principle of own-payoff maximization tells them to do so.

The remainder of the paper is organized as follows. Section 2 discusses the related experimental literature. Section 3 describes the experimental features and setup. Section 4 generates behavioral prediction. Section 5 presents the results. Section 6 concludes

\section{Related Experiments}

Despite the mounting evidence that economic agents exhibit social preferences (Fehr and Schmidt, 1999; Bolton and Ockenfels, 2000; Charness and Rabin, 2002), scholars have only recently started to focus on the analysis and implications of the incomplete contract approach when the neoclassical self-interest paradigm does not hold (Hart, 2008; Hart and Moore, 2008). Furthermore there is virtually no experimental evidence testing the predictions of this kind of models.

One notable exception and the closest antecedent to this paper is Fehr et al. (2008b) who use experiments to compare different allocations of ownership rights. ${ }^{3}$ The key finding of this study, which contrasts with the theoretical prediction of the property rights model developed by Hart (1995), is that joint ownership is the most efficient ownership structure. The superiority of joint ownership in the experimental setting can be explained by the fact that it makes better use of fairness as an enforcement device than alternative ownership structures. Our paper looks at the extent to which power imbalances between trade partners affect relationship-specific investments. Although some of the issues we are interested in are similar to those explored in Fehr et al. (2008b), our experimental setup differs markedly from theirs.

First, we employ a non-linear payoff function instead of a linear one. Players receive payoffs based on a Cobb-Douglas transformation of their investments into a physical asset. Investments are therefore complements at the margin, and the equilibrium outcome is interior rather than on the boundary

\footnotetext{
${ }^{3}$ Another exception is the study by Fehr et al. (2008a) which provides experimental evidence in line with the idea of Hart and Moore (2008) that competitively determined contracts constitute a reference point for trading relationships.
} 
of the strategy space. Second, in our experiment players invest simultaneously while Fehr et al. (2008b) look at the case of sequential investments. Due to the simultaneous-move design, the only asymmetry between players is due to the asymmetric sharing rule. Hence, we minimize confounding behavioral effects such as trust or reciprocity. Third, we not only observe players' investment strategies, but also players' beliefs about their opponents' investment strategies. This allows us to learn more about the motives of the players.

A key finding of our incomplete contract experiment is that people tend to disregard inequality, instead making investment choices that improve social welfare. Relatedly, Charness and Grosskopf (2001) present evidence that most people in simple experimental games are prepared to make monetary sacrifices to help other persons, but only few sacrifice money merely to achieve equality of payoffs. Kritikos and Bolle (2001) show that participants in binary-choice dictator games which allow for discrimination between different types of distributional concerns are efficiency rather than equity-oriented. Finally, Engelmann and Strobel (2004) study simple one-shot distribution experiments, showing that a combination of efficiency concerns, maximin preferences, and selfishness can rationalize most of their data while inequality aversion cannot explain some important patterns. The results presented here confirm these findings, but in a new and different context. In particular, ours is the first study showing that concerns for social welfare are key determinants of investment behavior in a world of costly contracting.

Our paper also makes contact with several other strands of the experimental literature. Both our study and that by Fehr et al. (2008b) has been preceded by a small experimental literature on hold-up problems. A hold-up problem arises when part of the return on an agent's relationship-specific investment is expropriated by her trading partner in an ex-post process of negotiation. In an early experiment, Hacket (1994) showed that agents who invest relatively more tend to receive larger shares of ex-post surplus. The fact that higher ex-ante investments are rewarded through more favorable expost sharing agreements mitigates problems of underinvestment and hold-up, a finding which is also at the heart of the study by Oosterbeek et al. (2003). Gantner et al. (2001) study simple bargaining games with prior production. Their key finding is a significant correlation between a player's input into the production process and the output share she claims during the bargaining process, which suggests that equity considerations matter in this context. 
The games we analyze also share some features with public good games, which have been extensively explored in the laboratory. A common finding is that people cooperate more than in the Nash equilibrium, although cooperation decays during the experiment. Our symmetric partnership structure is strongly reminiscent of non-linear public good games with interior Nash equilibria (for a review of the relevant experimental literature see Laury and Holt, 2008). The analogy is less evident when it comes to the asymmetric partnership setup; this treatment is evocative of a (partially) excludable public good game, i.e., one player can exclude the other from enjoying part of the public good.

The final part of our experiment also bears some aspects of a gift-exchange game. Fehr et al. (1998) find that gift exchange actually works in the laboratory, although it is not a subgame perfect equilibrium.

\section{Implementation of the Experiment}

\subsection{Baseline Game and Experimental Design}

Consider the following model. There are two agents, $A$ and $B$. Each agent $i \in\{A, B\}$ owns $M_{i}$ units of initial endowment of a private good. Agents choose how to split $M_{i}$ between their own consumption $\left(x_{i}\right)$ and investment in a production process $\left(I_{i}\right)$. The monetary value of the output produced by the investments of $A$ and $B$ is given by $Q\left(I_{A}, I_{B}\right)=\vartheta I_{A}^{\alpha} I_{B}^{\beta}$, where $\vartheta>0, \alpha>0$ and $\beta>0$ are productivity parameters. A sharing rule (or an allocation of power) determines how the monetary value of output is split between the agents. Let $\pi_{A}=\pi$ be the share that goes to $A$, and let $\pi_{B}=1-\pi$ be the share that goes to $B$. Each agent $i$ maximizes a payoff function of the form $U_{i}\left(I_{A}, I_{B}\right)=x_{i}+\pi_{i} Q\left(I_{A}, I_{B}\right)$ subject to the constraint $M_{i}=x_{i}+I_{i}$. Throughout the paper, we focus on environments in which the two agents are symmetric in productive terms, i.e. $\alpha=\beta$. For simplicity of notation, we will only refer to $\alpha$ hereafter.

We report data from an experiment based on the above basic model. The experiment was run at the University of Jena (Germany) in June and July 2008and was computerized using z-Tree (Fischbacher, 2007). A total of 146 participants, recruited with Orsee (Greiner, 2004), took part in the experiment. A translation of the instructions can be found in Appendix $\mathrm{B}$. 


\begin{tabular}{l|c|c|c|c} 
Configuration & SYM & ASYM & FLEX & $n$ \\
\hline conflict (-C) & SYM-C & ASYM-C & FLEX-C, choice between & 8 sessions \\
$\vartheta=24.83, \alpha=0.359$ & $\pi=0.491$ & $\pi=0.708$ & $\pi=0.491$ and $\pi=0.708$ & 70 participants \\
\hline no conflict (-NC) & SYM-NC & ASYM-NC & FLEX-NC, choice between & 8 sessions \\
$\vartheta=14, \alpha=0.41$ & $\pi=0.483$ & $\pi=0.748$ & $\pi=0.483$ and $\pi=0.748$ & 76 participants \\
\hline
\end{tabular}

TABLE 1: List of experimental treatments

Table 1 is useful in explaining the general structure of the experiment.

Participants were assigned to one of our two configurations: conflict and no conflict. Within each configuration, participants experience three types of treatments: an asymmetric contract (ASYM), a symmetric contract (SYM) and a flexible contract (FLEX). In ASYM and SYM, the sharing rule used to divide the benefits from joint production is exogenously fixed. We will refer to these two configurations as fixed contracts. ASYM and SYM represent exemplifications of situations characterized by power balance and imbalance respectively. In FLEX participants can choose either a symmetric or an asymmetric contract. If, in FLEX, both participants choose the same sharing rule then this rule is adopted. In case of disagreement the asymmetric rule ASYM is used as the default rule. The FLEX treatment allows to analyze whether participants want to switch from an asymmetric to a symmetric power structure.

At the beginning of each session we decided randomly whether participants would first play 10 rounds of ASYM (this happened in 7 sessions) and then 10 rounds of SYM, or whether to use the opposite sequence (this happened in 9 sessions). After having experienced 10 rounds of SYM and 10 rounds of ASYM participants played 10 rounds of FLEX. 4 Participants were rematched randomly after each round. Although different parameters $(\vartheta$ and $\alpha)$ and sharing rules are employed in conflict and no conflict, equilibrium predictions for the two configurations differ mainly in the flexible contract treatment. With the conflict-parameters there is a conflict of interest between the two players: in FLEX-C the selfish $A$-players prefer the asymmetric contract while $B$-players prefer the symmetric contract. With the no conflict-parameters this is not the case: in FLEX-NC both types of players, $A$ and $B$, prefer the symmetric contract. We will explain this in more detail when illustrating this treatment. When discussing asymmetric

\footnotetext{
${ }^{4}$ In one session of the experiment we played 12 and not 10 rounds of each contract.
} 
contracts, we will refer to type $A$ players as strong and to type $B$ players as weak. We now turn to a more detailed description of the experiment.

\subsection{Fixed Contracts}

In each treatment, players simultaneously invest into joint production under either symmetric or asymmetric sharing rules. Under symmetric sharing rules ( $\pi^{S Y M}$ is 0.491 or 0.483 ), each player is entitled to an almost equal share of the total monetary output. Under asymmetric sharing rules $\left(\pi^{A S Y M}\right.$ is 0.708 or 0.748 ), the strong player receives a substantially larger portion of the total output. In our experiment, players choose integer investment numbers only (multiples of 50 from 0 to 500) and derive their payoffs from payoff tables (see table 2 for an example). The parameter values $(\vartheta$ and $\alpha$ ) used in our treatments are given in Table 1. $M_{i}$ is always 500. Payoffs in the experiment are rounded to integers. Furthermore, in the experiment the values of the investments (0 to 500) are replaced by consecutive numbers (1 to 11).

Discretizing a continuous problem and presenting it with the help of payoff tables has both advantages and disadvantages. A key advantage is that it allows us to elicit players' expectations in a natural way. In each round of the experiment, players are asked to click on a row they might want to choose and on a column they think their opponents might select. These rows and columns and their intersection are then highlighted on the computer screen. Participants can experiment by clicking on rows and columns as often as they want until they are satisfied with their choices and expectations. Only when a participant clicks on an "OK" button does she proceed to the result stage of the round. This feature not only allows us to check for the consistency of players' expectations and behavior, but it also promotes a more thoughtful decision-making process. Table 2 presents an example of a decision screen in the experiment.

The disadvantage of discretizing a continuous problem is that it quickly leads to a large number of equilibria. If we want to have a clear equilibrium prediction, and still present payoffs in the form of tables, then we have to live with a parameter space that is considerably restricted. In particular, we can only use values of $\pi$ which are bounded away from $1 / 2$. Hence, when we call a sharing rule "symmetric" then this is only an approximation; $\pi=0.491$ and $\pi=0.483$ are as close as we can get to $1 / 2$.

We illustrate the best reply functions for ASYM and SYM, under either 


\begin{tabular}{|c|c|c|c|c|c|c|c|c|c|c|c|}
\hline \multicolumn{12}{|c|}{ expected choice of the other player } \\
\hline & 1 & 2 & 3 & 4 & 5 & 6 & 7 & 8 & 9 & 10 & 11 \\
\hline 1 & $500^{500}$ & $500^{450}$ & $500^{400}$ & $500^{350}$ & $500^{300}$ & $500^{250}$ & $500^{200}$ & $500^{150}$ & $500^{100}$ & $500^{50}$ & $500^{0}$ \\
\hline 2 & $450^{500}$ & $742^{570}$ & $824^{554}$ & $883^{528}$ & $930^{498}$ & $970^{464}$ & $1005^{429}$ & $1036^{392}$ & $1065^{354}$ & $1092^{315}$ & $1117^{275}$ \\
\hline 3 & $400^{500}$ & $774^{604}$ & $880^{598}$ & $955^{579}$ & $1015^{554}$ & $1067^{525}$ & $1112^{494}$ & $1152^{400}$ & $1189^{425}$ & $1223^{390}$ & $1255^{353}$ \\
\hline 4 & $350^{500}$ & $783^{628}$ & $905^{629}$ & $992^{615}$ & $1062^{594}$ & $1121^{568}$ & $1173^{540}$ & $1220^{509}$ & $\frac{478}{1263}$ & $1302^{443}$ & $1339^{408}$ \\
\hline 5 & $300^{500}$ & $780^{648}$ & $915^{654}$ & $1012^{644}$ & $1089^{625}$ & $1155^{603}$ & $1213^{576}$ & $1265^{548}$ & $1312^{517}$ & $1356^{485}$ & $1397^{452}$ \\
\hline$\sum_{0}^{5}$ & $250^{500}$ & $770^{664}$ & $917^{675}$ & $1021^{668}$ & $1105^{653}$ & $1176^{632}$ & $1239^{608}$ & $1295^{581}$ & $1347^{552}$ & $1394^{522}$ & $1438^{490}$ \\
\hline うे & $200^{500}$ & $755^{679}$ & $912^{694}$ & $1023^{690}$ & $1113^{676}$ & $1189^{658}$ & $1256^{635}$ & $1316^{610}$ & $1371^{583}$ & $1421^{554}$ & $1468^{523}$ \\
\hline 8 & $150^{500}$ & $736^{692}$ & $902^{710}$ & $1020^{709}$ & $1115^{698}$ & $1195^{681}$ & $1266^{660}$ & $1329^{636}$ & $1387^{610}$ & $1441^{582}$ & $1490^{553}$ \\
\hline 9 & $100^{500}$ & $715^{704}$ & $889^{725}$ & $1013^{726}$ & $1112^{717}$ & $1197^{702}$ & $1271^{683}$ & $1337^{660}$ & $1398^{635}$ & $1454^{608}$ & $1506^{580}$ \\
\hline 10 & $\mathbf{5 0}^{500}$ & $692^{715}$ & $873^{740}$ & $1002^{743}$ & $1106^{735}$ & $1194^{722}$ & $1271^{704}$ & $1341^{682}$ & $1404^{658}$ & $1463^{633}$ & $1517^{605}$ \\
\hline 11 & $\mathbf{0}^{500}$ & $667^{725}$ & $855^{753}$ & $989^{758}$ & $1097^{752}$ & $1188^{740}$ & $1268^{723}$ & $1340^{703}$ & $1406^{680}$ & $1467^{655}$ & $1524^{628}$ \\
\hline
\end{tabular}

In this example a participant has clicked on " 3 " in the left column to indicate her own choice. As a result the corresponding row is shown in red. She has also clicked on "9" in the top row to indicate her expectations about the choice of the other player. As a result this column is shown in red and the intersecting pair of payoffs is highlighted with a blue circle. The participant can now click on the OK-button to continue to the next stage. She can also wait and adjust her choices and expectations. Own payoffs are shown in boldface in the bottom left part of each cell of the table, the other payoffs are shown in a smaller font in the top right part.

TABLE 2: An example of a decision screen in the experiment
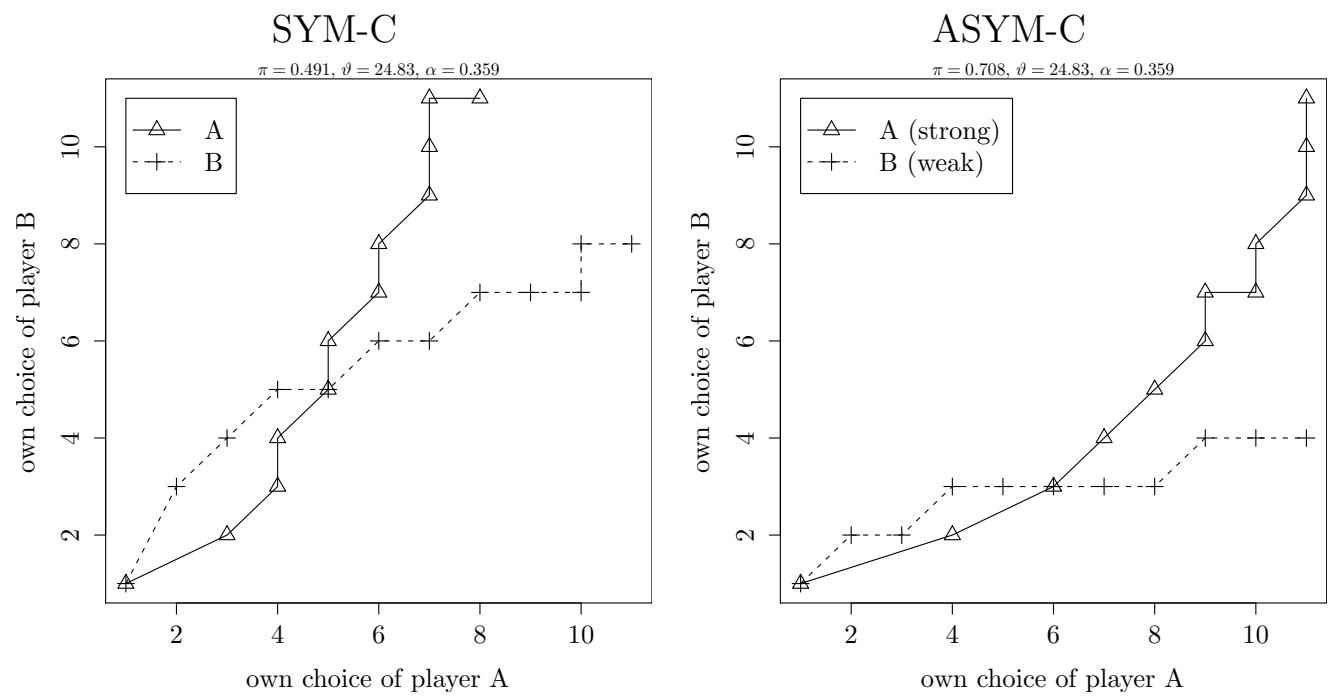

Figure 1: Best reply functions in SYM-C and ASYM-C with conflict 

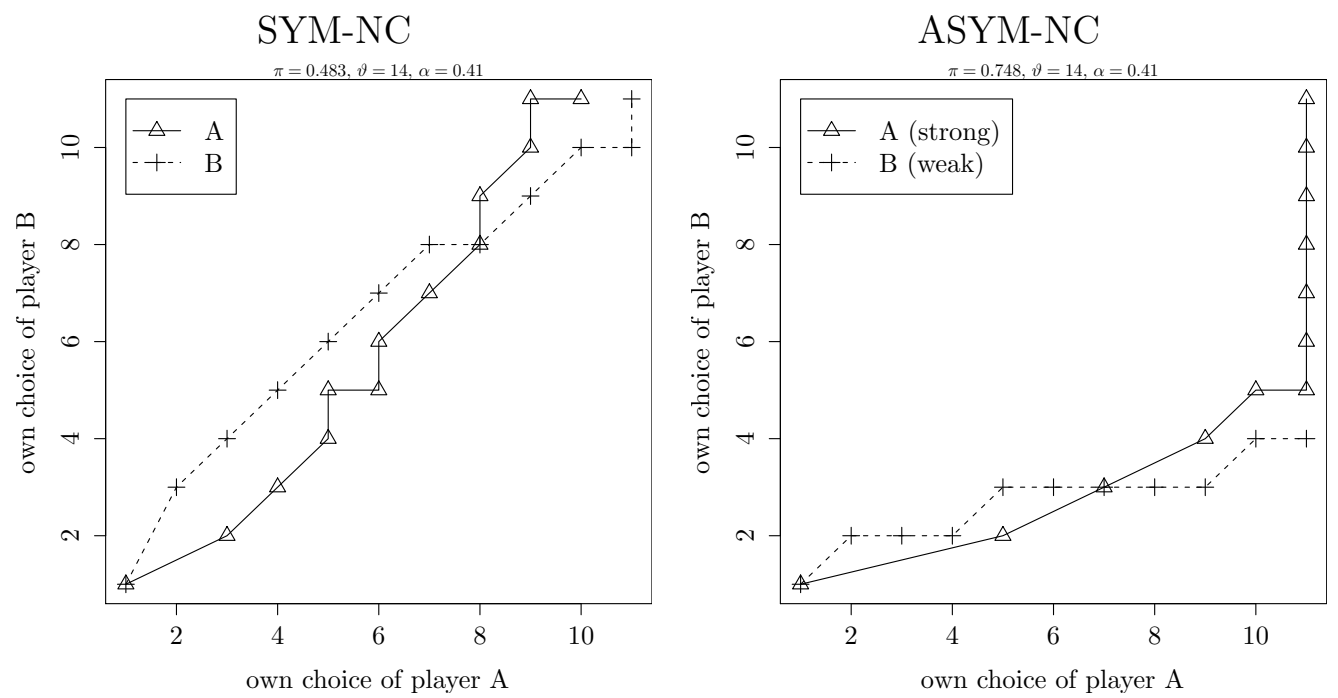

Figure 2: Best reply functions in SYM-NC and ASYM-NC with no conflict

conflict or no conflict, in Figures 1 and 2, assuming that individuals are motivated purely by self-interest. For each situation there is an interior Nash equilibrium in which both players invest part of their endowment into joint production; there is also an equilibrium in which both players invest zero. We note that no sharing rule induces first best investments. Intuitively, this is because players do not capture the full marginal returns on their investments. As a consequence, equilibrium investment levels are inefficiently low. However, some sharing rules provide better investment incentives than others. In particular, if participants in the experiment are motivated by selfinterest and select interior equilibria, then asymmetric sharing rules lead to lower aggregate investments than symmetric sharing rules. 5

We now turn our attention to payoff distributions. If players follow standard equilibrium predictions and select interior equilibria, then asymmetric sharing rules not only imply lower aggregate investments, but also unequal payoff distributions. This is illustrated in Figure 3, which shows the convex hull of the feasible payoff pairs for both treatments, under either conflict or

\footnotetext{
${ }^{5}$ Theoretically, if players simultaneously choose $I_{A}$ and $I_{B}$ to respectively maximize $M_{A}-I_{A}+\pi \vartheta I_{A}^{\alpha} I_{B}^{\beta}$ and $M_{B}-I_{B}+(1-\pi) \vartheta I_{A}^{\alpha} I_{B}^{\beta}$, then the sharing rule that maximizes joint payoffs and provides optimal investment incentives is given by

$$
\pi^{*}=\frac{1}{1+\varphi} \quad \text { where } \quad \varphi=\sqrt{\frac{(1-a) b}{(1-b) a}}
$$

If players are symmetric in productive terms $(a=b)$, then $\varphi=1$ and the optimal sharing rule is $\pi=1 / 2$.
} 

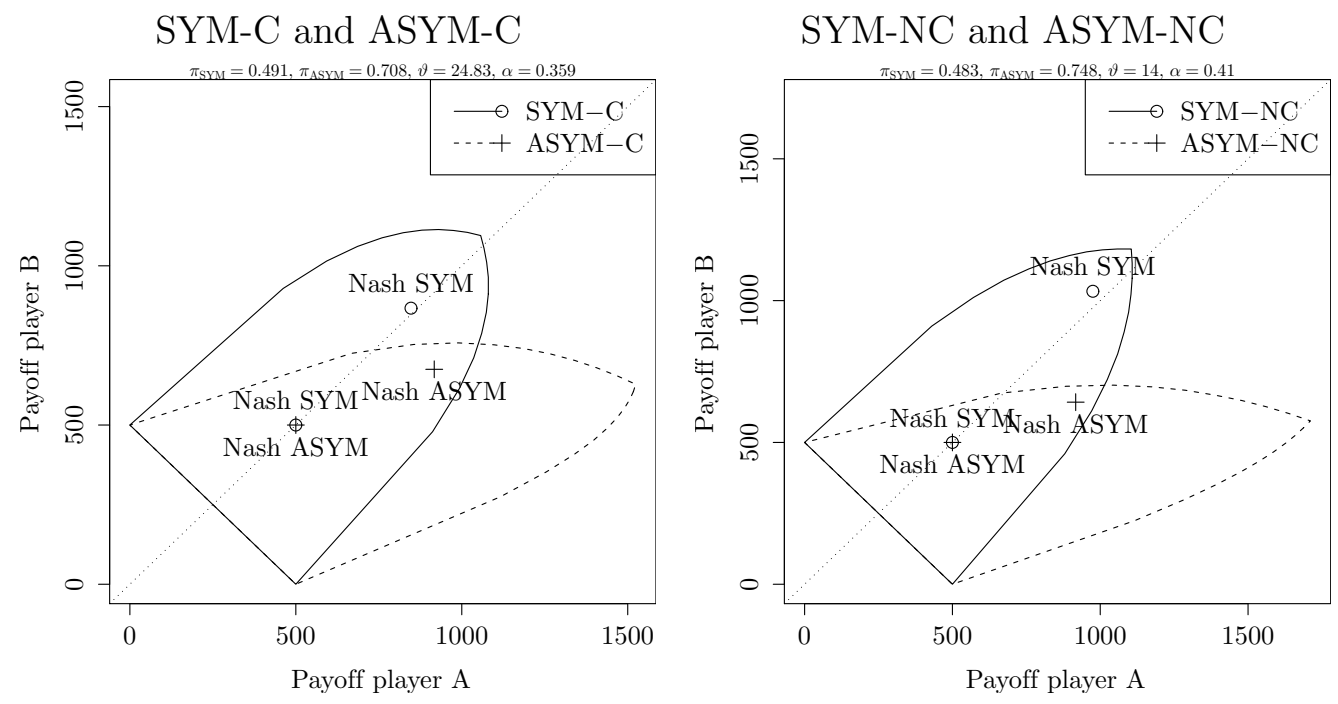

Figure 3: Convex hull of payoff possibilities

no conflict. The dashed line marks the set of all payoff combinations that can be obtained with asymmetric sharing rules. The solid line shows the set of all payoff combinations that can be achieved with symmetric sharing rules. Equilibrium payoff pairs implied by asymmetric sharing rules are marked with a "+", while those implied by symmetric sharing rules are marked with a "o". If players choose interior equilibria then ASYM sharing rules give rise to rather large payoff differences. The interior equilibrium payoffs of type $A$ players exceed those of type $B$ players by about $36 \%$ in conflict and $43 \%$ in no conflict. For the sharing rules that we call SYM there is still a deviation, but it is much smaller: $2 \%$ in conflict and $6 \%$ in no conflict.

\subsection{Flexible Contracts}

After having played the fixed contract game with 10 rounds of SYM and 10 rounds of ASYM sharing rules, in FLEX players can choose between ASYM and SYM. The default rule is always ASYM. If both players prefer the same contract (either SYM or ASYM), then this contract is implemented; if players disagree, then the status quo contract ASYM is used. We use the strategy method and ask players in each period whether they prefer SYM or ASYM and, simultaneously, which investment they would choose under ASYM and under SYM. When both players have made their choice we reveal the chosen contract, investments and payoffs.

Which contracts should players choose? In Figure 3 we notice that in 
both conditions, conflict and no conflict, a weak $(B)$ player prefers SYM over ASYM in equilibrium. Intuitively, this is because both total investments and the weak player's share increase from ASYM to SYM. For the strong $(A)$ player the situation is different: On the one hand, an agreement to implement a more equitable sharing rule reduces a strong $(A)$ player's share of the total surplus ("surplus division effect"). On the other hand, such an agreement induces the weak $(B)$ player to invest more into joint production ("investment effect"). Under conflict, the surplus division effect dominates the investment effect, and so it is rational for a strong $(A)$ player to veto the implementation of a more equitable sharing rule. Under no conflict, the investment effect dominates the surplus division effect, and hence it is rational for a strong (A) player to give up her power in favor of a symmetric sharing rule.

\section{Behavioral Predictions}

Our discussion and predictions so far are based on the assumption of common knowledge of rationality and selfishness of all players. However, experimental evidence suggests that not all individuals simply maximize monetary payoffs. Two features of our basic model make it conceivable that behavioral motives might enter players' investment decisions:

The allocation under standard equilibrium predictions is inefficient and unequal. Players might therefore be concerned about social efficiency or reveal an aversion towards inequality. In this section we will show that these different types of social preferences call for quite different investment choices.

To generate behavioral predictions we follow a model of social preferences as proposed by Charness and Rabin (2002). While the players in our experiment choose integer investment numbers only, it is instructive to generate behavioral predictions based on the continuous choice problem underlying the experiment. Letting

$U_{A}\left(I_{A}, I_{B}\right)=M-I_{A}+\pi \vartheta\left(I_{A} I_{B}\right)^{\alpha} \quad$ and $\quad U_{B}\left(I_{A}, I_{B}\right)=M-I_{B}+(1-\pi) \vartheta\left(I_{A} I_{B}\right)^{\alpha}$

denote player $A$ 's and $B$ 's monetary payoffs, we suppose that players' preferences are given by:

$$
V_{A}\left(I_{A}, I_{B}\right)=(\rho \cdot r+\sigma \cdot s) \cdot U_{B}\left(I_{A}, I_{B}\right)+(1-\rho \cdot r-\sigma \cdot s) \cdot U_{A}\left(I_{A}, I_{B}\right)
$$


and

$$
V_{B}\left(I_{A}, I_{B}\right)=(\rho \cdot s+\sigma \cdot r) \cdot U_{A}\left(I_{A}, I_{B}\right)+(1-\rho \cdot s-\sigma \cdot r) \cdot U_{B}\left(I_{A}, I_{B}\right)
$$

where $r=1$ and $s=0$ if $U_{A}(\cdot)>U_{B}(\cdot), r=0$ and $s=1$ if $U_{A}(\cdot)<U_{B}(\cdot)$, and $r=0$ and $s=0$ if $U_{A}(\cdot)=U_{B}(\cdot)$. This is basically the model of Charness and Rabin (2002), except that, in this simultaneous move game, we leave out the term for reciprocity. The parameters $\rho$ and $\sigma$ allow for a range of different "distributional preferences". We focus here on "competitive preferences", "difference-averse preferences" and "social-welfare preferences". Competitive preferences correspond to $\sigma \leq \rho \leq 0$, meaning that each player prefers to do as well as possible in comparison to her opponent, while also caring directly about her own payoff. Models of inequity (difference) aversion (Fehr and Schmidt, 1999; Bolton and Ockenfels, 2000) assume that people prefer to minimize disparities between their own payoffs and those of other people. Inequity aversion corresponds to $\sigma<-\rho<0$. That is, people suffer utility losses from both disadvantageous and advantageous payoff disparities, but suffer more from disparities that are to their disadvantage. By contrast, the notion of social-welfare preferences captures the idea that individuals prefer higher payoffs for themselves and for other persons, but are more concerned about own payoffs when they are disadvantaged compared to others (Charness and Rabin, 2002). Concerns for social-welfare can be represented by assuming that $1>\rho>\sigma>0$. We now explain how these three different forms of distributional preferences would theoretically affect players' incentives to invest into joint production.

Suppose that the sharing rule used to divide output is exogenous. As a benchmark, consider the equilibrium investments under the assumption of selfishness of all players. In this case, the investments $I_{A}$ and $I_{B}$ are chosen simultaneously and non-cooperatively to maximize $U_{A}\left(I_{A}, I_{B}\right)$ and $U_{A}\left(I_{A}, I_{B}\right)$, respectively. 6 We have:

Proposition 1 If the participants exhibit self-interested preferences $(r=s=$ $0)$, then there exists a unique interior Nash equilibrium in pure strategies in which the participants' investment levels are given by

$$
I_{A}^{s}=\left[\alpha \vartheta \pi^{1-\alpha}(1-\pi)^{\alpha}\right]^{\frac{1}{1-2 \alpha}} \quad \text { and } \quad I_{B}^{s}=\left[\alpha \vartheta \pi^{\alpha}(1-\pi)^{1-\alpha}\right]^{\frac{1}{1-2 \alpha}}
$$

\footnotetext{
${ }^{6}$ In the discussion to follow, we will ignore the existence of an equilibrium in which both players invest zero.
} 
Proof. See Appendix A.1.

We next consider how distributional concerns would alter the players' investment incentives. As we will demonstrate below, the equilibrium investments of individuals with distributional preferences depend on the degree of asymmetry in the sharing rule $\pi$. Without loss of generality, we restrict our attention to parameter values satisfying $\pi \geq 1 / 2$, i.e., the case in which any asymmetry in the sharing rule favors player $A$ and discriminates against player $B$. For algebraic convenience, define

$$
\kappa_{A}=\frac{(1-\rho) \pi+\rho(1-\pi)}{1-\rho} \quad \text { and } \quad \gamma_{B}=\frac{(1-\sigma)(1-\pi)+\sigma \pi}{1-\sigma}
$$

and

$$
\varepsilon=\frac{2 \pi-1}{\alpha}
$$

We have the following:

Proposition 2 Suppose that players exhibit distributional preferences $(r \neq 0$ and $s \neq 0)$. Assume $\pi \geq 1 / 2$ and define:

$$
\bar{\pi}=\frac{\mu}{1+\mu} \quad \text { where } \quad \mu=\frac{(1-\sigma)[(1-\alpha)(1-\rho)+\rho \alpha]}{(1-\rho)[(1-\alpha)((1-\sigma)+\sigma \alpha]}>1.7
$$

(a) If the sharing rule $\pi$ is sufficiently bounded away from one-half, $\pi \in$ $[\bar{\pi}, 1)$, then there exists a unique interior Nash equilibrium in pure strategies in which the players' investment levels are given by

$$
I_{A}^{*}=\left[\alpha \vartheta\left(\kappa_{A}\right)^{1-\alpha}\left(\gamma_{B}\right)^{\alpha}\right]^{\frac{1}{1-2 \alpha}} \quad \text { and } \quad I_{B}^{*}=\left[\alpha \vartheta\left(\kappa_{A}\right)^{\alpha}\left(\gamma_{B}\right)^{1-\alpha}\right]^{\frac{1}{1-2 \alpha}}
$$

(b) If the sharing rule $\pi$ is sufficiently close to one-half, $\pi \in[1 / 2, \bar{\pi})$, then there exists a closed set of Pareto-rankable Nash equilibria in pure strategies. In the most efficient equilibrium the players' investment levels are given by

$$
\bar{I}_{A}=\left[\alpha \vartheta\left(\kappa_{A}\right)^{1-\alpha}\left(\kappa_{A}-\varepsilon\right)^{\alpha}\right]^{\frac{1}{1-2 \alpha}} \quad \text { and } \quad \bar{I}_{B}=\left[\alpha \vartheta\left(\kappa_{A}\right)^{\alpha}\left(\kappa_{A}-\varepsilon\right)^{1-\alpha}\right]^{\frac{1}{1-2 \alpha}} \text {. }
$$

In the least efficient equilibrium the players' investment levels are given

\footnotetext{
${ }^{7}$ That we have $\mu>1$ follows from the assumption of our distributional model that $\rho>\sigma$. Note that this assumption is satisified irrespective of whether one is interested in "competitive preferences", "difference-averse preferences" or "social welfare preference".
} 


$$
\begin{aligned}
& \text { by } \\
& \underline{I}_{A}=\left[\alpha \vartheta\left(\gamma_{B}+\varepsilon\right)^{1-\alpha}\left(\gamma_{B}\right)^{\alpha}\right]^{\frac{1}{1-2 \alpha}} \quad \text { and } \quad \underline{I}_{B}=\left[\alpha \vartheta\left(\gamma_{B}+\varepsilon\right)^{\alpha}\left(\gamma_{B}\right)^{1-\alpha}\right]^{\frac{1}{1-2 \alpha}} \text {. }
\end{aligned}
$$

\section{Proof. See Appendix A.2.8}

If the sharing rule used to divide output is sufficiently asymmetric, then the players' best response functions are well behaved and a unique equilibrium in pure strategies exists [part (a) of the proposition]. Conversely, if the sharing rule used to divide output is sufficiently close to one-half, then there exists a set of Pareto-rankable Nash equilibria in pure strategies [part (b) of the proposition]. In each equilibrium, the investments chosen by $A$ and $B$ lead to an equalization of their respective payoffs.

In order to generate behavioral predictions, we now contrast the investment incentives of self-interested players with those of individuals who are either inequity-averse or care about social welfare. In so doing, we focus purely on the parameters used in our experiment. We use the term simultaneous overinvestment to describe a situation in which the investments chosen by both players exceed those of self-interested individuals. Similarly, the notion simultaneous underinvestment denotes outcomes in which both players choose investment levels that are lower than those chosen by their selfish counterparts. For sharing rules that are bounded away from one-half, we have:

Prediction 1 (Asymmetric Sharing Rules) If the sharing rule used to divide output is asymmetric $(\pi=0.708$ in $A S Y M-C$ and $\pi=0.748$ in $A S Y M$ NC) then:

(a) If players are motivated by inequity aversion $(\sigma<-\rho<0)$ or have competitive preferences ( $\sigma \leq \rho \leq 0)$, then there is simultaneous underinvestment in equilibrium.

(b) If players are concerned about social-welfare $(1 \geq \rho \geq \sigma>0)$, then there is simultaneous overinvestment in equilibrium.

\footnotetext{
${ }^{8}$ For the sake of simplicity, the proposition establishes all possible equilibrium configurations for the case in which $\gamma_{B}$ is strictly positive. This requires that $\sigma>\hat{\sigma}$, where $\hat{\sigma}=-\frac{1-\pi}{2 \pi-1}$. All behavioral predictions that are to follow continue to hold in the case where $\sigma \leq \hat{\sigma}$. A detailed proof is contained in Appendix A.
} 
Proof. See Appendix A.3.

These results are driven by the complementarity in our investment game. Suppose both players display inequity aversion and consider the self-interest Nash equilibrium prediction as a starting point. 9 The only way a player of type $B$ can reduce payoff differences is by decreasing her investment; knowing this, and given that $A$ is less concerned than $B$ about inequality $(\sigma<-\rho<$ $0)$, A's best reply is to also lower her investment. The iteration of this kind of reasoning results in a Pareto-inferior equilibrium with respect to the Nash prediction based on self-interested players. Now consider players who display social-welfare preferences. Then player $A$ has an incentive to raise her investment, with respect to the rational Nash equilibrium, thus increasing joint payoffs while keeping ahead of her opponent. Knowing this, B's best reply is to raise her investment as well, thus provoking an even higher increase in $A$ 's choice which augments her own payoff. This leads to an equilibrium that Pareto-dominates the self-interest Nash prediction.

The above discussion assumes that the sharing rule used to divide output is sufficiently asymmetric. For sharing rules that are close to one-half, we have the following:

Prediction 2 (Symmetric Sharing Rules) If the sharing rule used to divide output is close to one-half ( $\pi=0.491$ in $S Y M-C$ and $\pi=0.483$ in $S Y M-N C$ ) then:

(a) If players have competitive preferences $(\sigma \leq \rho \leq 0)$, then there is simultaneous underinvestment in equilibrium.

(b) If players are motivated by inequity aversion $(\sigma<-\rho<0)$, then there can be simultaneous underinvestment and simultaneous overinvestment in equilibrium.

(c) If players are concerned about social-welfare $(1 \geq \rho \geq \sigma>0)$, then there is simultaneous overinvestment in equilibrium.

Proof. See Appendix A.4.

While our theoretical predictions are derived from the continuous choice problem that underlies our experiment, they carry over to the discrete investment game that our players face in the laboratory. Assuming that players

\footnotetext{
${ }^{9}$ Similar points hold when individuals exhibit competitive preferences.
} 
Simultaneous underinvestment (1) Simultaneous overinvestment (2)

Parameter values Consistent with Parameter values Consistent with

Asymmetric sharing rules

ASYM-C $(\pi=0.708) \quad \sigma<-0.05, \rho<0.38 \quad$ IA and CP $\quad \sigma>0.03, \rho>-0.11 \quad$ CSW

ASYM-NC $(\pi=0.748) \quad \sigma<-0.03, \rho<0.46 \quad$ IA and CP $\quad \sigma>0.02, \rho>-0.20 \quad$ CSW

Symmetric sharing rules

SYM-C $(\pi=0.491) \quad \sigma<-0.51 \cdot \rho-0.06 \quad$ IA and CP $\quad \sigma>0.02-1.2 \cdot \rho \quad$ IA and CSW

SYM-NC $(\pi=0.483) \quad \sigma<0.05, \rho<-0.01 \quad$ CP $\quad \sigma>0.02, \rho>-0.05 \quad$ CSW

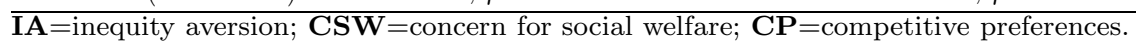

TABle 3: Behavioral Predictions

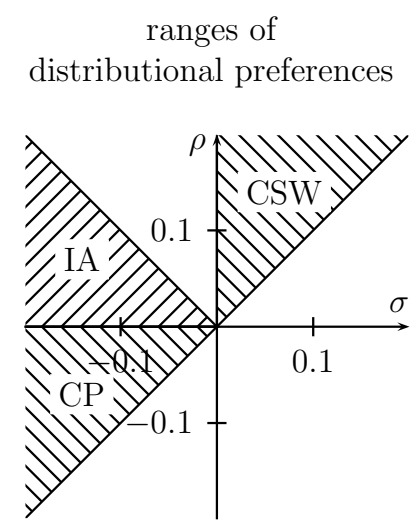

ranges consistent with
simultaneous underinvestment

ranges consistent with simultaneous underinvestment simultaneous overinvestment

$\mathbf{I A}=$ inequity aversion; $\mathbf{C S W}=$ concern for social welfare; $\mathbf{C P}=$ competitive preferences.

Figure 4: Behavioral Predictions — Illustration of Table 3

have distributional preferences, Table 3 gives necessary conditions on $\sigma$ and $\rho$ for the existence of an equilibrium in our discrete choice experiment in which both $A$ and $B$ either underinvest (column 1) or overinvest (column 2) compared to self-interested individuals. Figure 4 illustrates the table.

With the help of these conditions we can now relate behavior in the experiment to preferences. In all four treatments simultaneous overinvestment as an equilibrium outcome is consistent with concerns for social welfare. Conversely, simultaneous underinvestment as an equilibrium outcome is consistent with either a competitive preference or an intrinsic preference to minimize differences in payoffs.

Overall, our investment game with asymmetric sharing rules allows us to disentangle social-welfare concerns from inequality aversion and competitive preferences. Differently from numerous other experiments in which a Paretoimprovement also decreases inequality ${ }^{10}$, in our case the only way equally

\footnotetext{
${ }^{10}$ See Charness and Rabin (2002) for a discussion.
} 

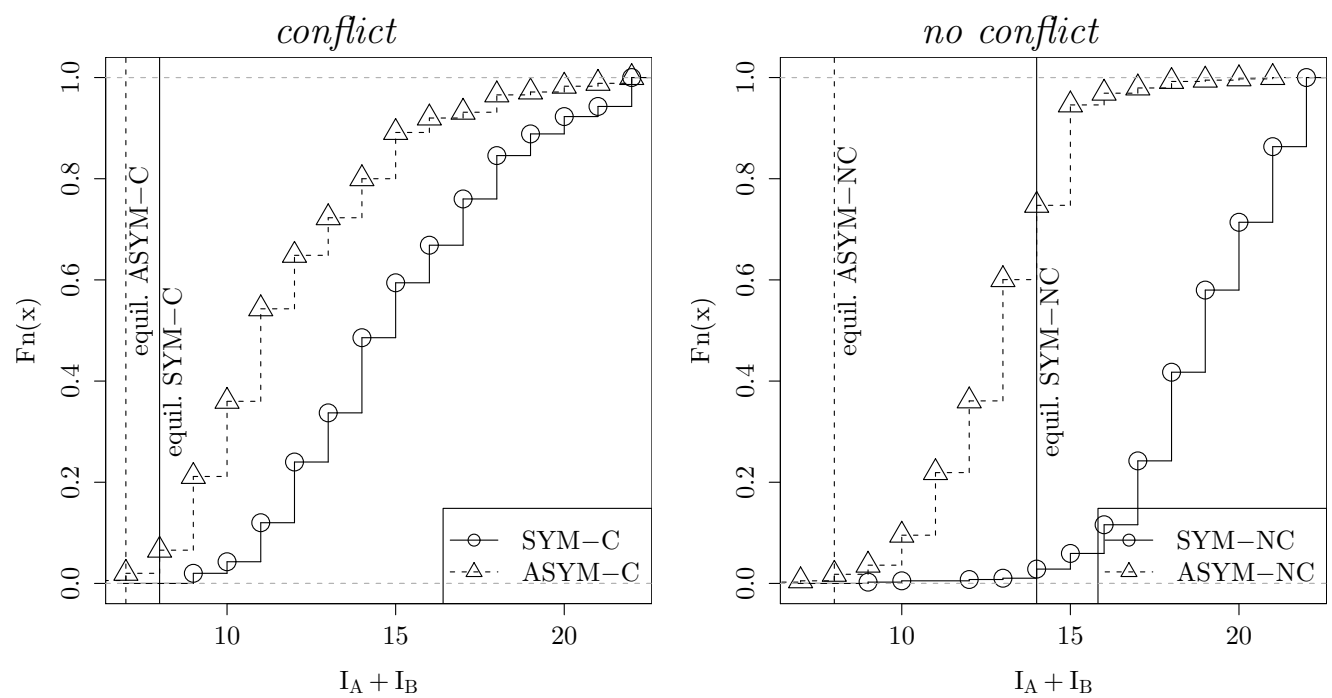

FiguRE 5: Distribution of investments under Fixed Contracts

inequality averse players can lower payoff differences in equilibrium is by investing even less efficiently than selfish individuals. On the other hand, if players are equally concerned about social-welfare they will in equilibrium raise their investment compared to self-interested players.

\section{Results}

We now turn to a detailed examination of the experimental data. We consider investment choices under fixed contracts in Section 5.1, discuss the consistency of expectations and behavior in Section 5.2, and examine the effects of endogenizing sharing rules in Section 5.3.

\subsection{Fixed Contracts}

We begin by examining investment choices when contracts are fixed. In so doing, we exploit the data collected during treatments ASYM and SYM for both configurations conflict and no conflict. As we mentioned earlier, if players follow standard equilibrium predictions, then no sharing rule would induce first best investments. However, symmetric sharing rules are predicted to provide better aggregate investment incentives than asymmetric sharing rules. This prediction is confirmed by our results. Figure 5 shows the cumulative distribution of investments in both treatments under conflict and no conflict respectively. Under both configurations we observe that aggregate 


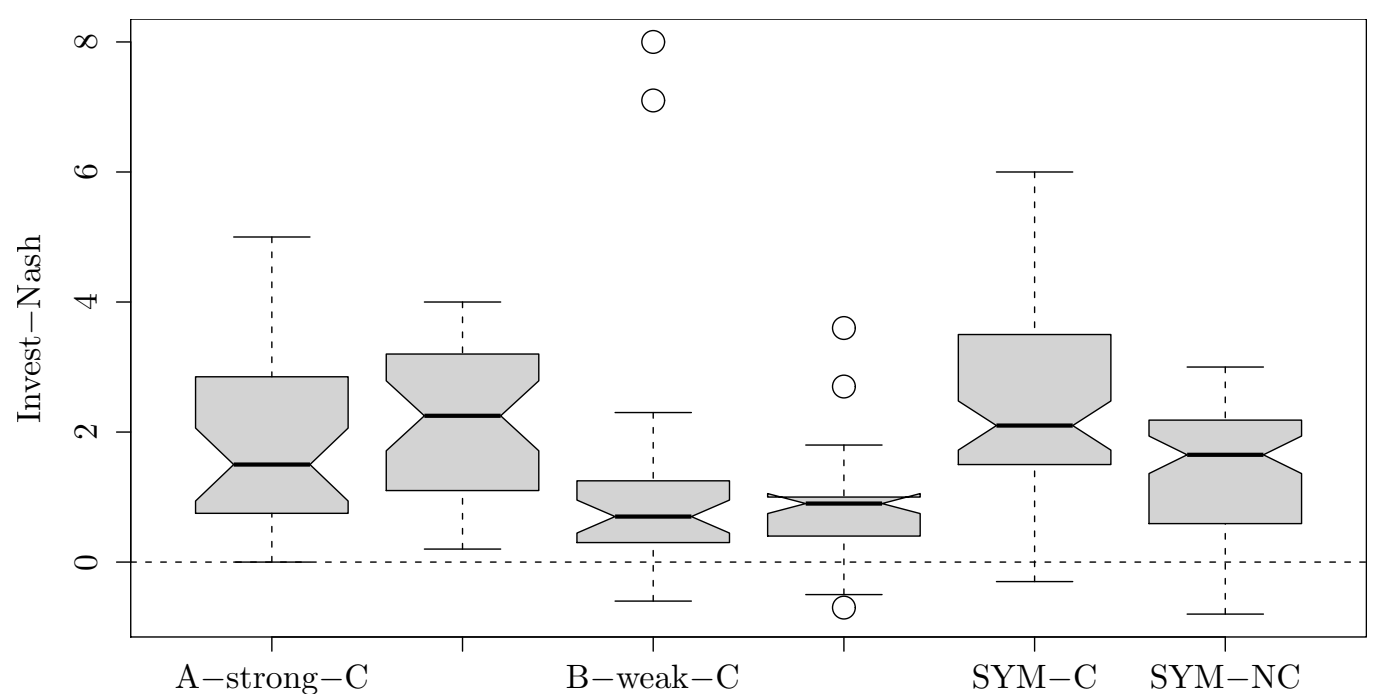

Notches extend to $\pm 1.58 \mathrm{IQR} / \sqrt{n}$ and indicate a $95 \%$ conf. interval for the difference in two medians (see Chambers et al., 1983).

FiguRE 6: Average investments (over Nash investment) per player

investments are substantially lower in ASYM, i.e. when one individual appropriates a large portion of the total benefits accruing from the partnership. This confirms one of the central insights of the modern property rights approach (Grossman and Hart, 1986; Hart and Moore, 1990), namely that the allocation of power in partnerships is important for investment incentives. We record this in the following.

Result 1 Aggregate investments are higher under symmetric sharing rules than under asymmetric sharing rules.

The key issue motivating our experiment lies in understanding the behavioral motives that enter partners' investment behavior under symmetric and asymmetric power structures. To get at this issue, we now compare investment behavior in the experiment with equilibrium investments of selfish players. Figure 6 shows the difference between average investment and Nash equilibrium investment for both players and both treatments (under both parameter configurations) as a boxplot. Note that these differences are fairly similar under conflict and no conflict. Both types of players invest more than predicted by Nash equilibrium, although overinvestment is higher among strong $(A)$ players or with a symmetric sharing rule. 11

\footnotetext{
${ }^{11}$ As previously mentioned, our SYM treatment is similar to a non-linear public good game with an interior equilibrium. A prominent experiment in this area is the study by
} 


\begin{tabular}{l||c|c|c|c|cc|c}
\hline & $\beta$ & $\sigma$ & $t$ & $p$ value & $95 \%$ conf & interval & pmvd \\
\hline 1 & 0.777 & 0.235 & 3.31 & 0.0010 & 0.316 & 1.24 & \\
$d_{S Y M}$ & 1.65 & 0.0904 & 18.3 & 0.0000 & 1.47 & 1.83 & 0.845 \\
$d_{\text {strong }}$ & 0.817 & 0.104 & 7.83 & 0.0000 & 0.612 & 1.02 & 0.155 \\
\hline
\end{tabular}

TABLE 4: Mixed effects estimation of equation 11 for no conflict

\begin{tabular}{l||c|c|c|c|cc|c}
\hline & $\beta$ & $\sigma$ & $t$ & $p$ value & $95 \%$ conf & interval & pmvd \\
\hline 1 & 0.522 & 0.182 & 2.88 & 0.0040 & 0.166 & 0.878 & \\
$d_{S Y M}$ & 0.963 & 0.0611 & 15.8 & 0.0000 & 0.843 & 1.08 & 0.351 \\
$d_{\text {strong }}$ & 1.51 & 0.0705 & 21.4 & 0.0000 & 1.37 & 1.65 & 0.649 \\
\hline
\end{tabular}

TABLE 5: Mixed effects estimation of equation 11 for conflict

We can provide a more formal analysis of the behavioral patterns observed in Figure 6. To do so, we call $I_{i j}$ the investment of player $i$ in period $j$ during a given treatment (either SYM or ASYM). Moreover, let $I^{N}$ be the respective Nash equilibrium investment levels. We then estimate the following equation:

$$
\bar{I}-I^{N}=\beta_{1}+\beta_{S Y M} \cdot d_{S Y M}+\beta_{\text {strong }} \cdot d_{\text {strong }}+u_{s}+u_{i j}
$$

Sessions are indexed with $s$, players are indexed with $i$, and different periods have the index $j$. To simplify the notation we do not write indices $i j$ for variables. Throughout the paper and unless specified otherwise we estimate mixed effects models with a random effect for session $u_{s}$ where we assume that error terms $u_{s}$ and $u_{i j}$ follow a normal distribution with mean zero.

The dummy variable $d_{S Y M}$ is one for symmetric power sharing and zero otherwise, $d_{\text {strong }}$ is one for the strong player (A) under asymmetric sharing rules and zero otherwise. The reference group is, hence, weak players (B) under asymmetric power sharing. We estimate equation (11) separately for conflict and no conflict. Results are shown in Tables 5 and 4.

To assess the impact of coefficients on the variance of our dependent variable we use as a measure of relative importance the proportional marginal value decomposition (pmvd) as proposed by Feldman (2005) using the implementation of Grömping (2007). Other measures of relative importance (such as lmr) yield similar results.

Isaac and Walker (1998), who analyze the effect of the location of the aggregate Nash equilibrium in the strategy space. In line with their findings, we observe that investments are closer to Nash equilibrium when the latter is closer to efficiency, i.e., overinvestment is lower under SYM-NC compared to SYM-C. 


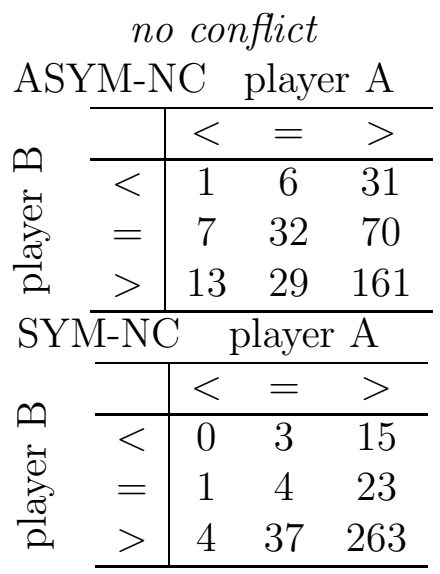

\begin{tabular}{|c|c|c|c|}
\hline & onf & & \\
\hline ASYM-C & & aye & A \\
\hline & $<$ & $=$ & $>$ \\
\hline$<$ & 1 & 6 & 29 \\
\hline$=$ & 4 & 15 & 82 \\
\hline$>$ & 9 & 29 & 213 \\
\hline SYM-C & & ayer & A \\
\hline & $<$ & $=$ & $>$ \\
\hline$<$ & 3 & 4 & 18 \\
\hline$=$ & 6 & 7 & 23 \\
\hline$>$ & 27 & 70 & 230 \\
\hline
\end{tabular}

The tables show for the different treatments the frequency of pairs of choices where players' investments were smaller $(<)$, equal $(=)$, or larger $(>)$ than Nash equilibrium investments.

TABLE 6: Frequencies of choices

Result 2 (a) Under both symmetric and asymmetric sharing rules, strong (A) and weak (B) players overinvest on average.

(b) With ASYM, strong (A) players overinvest more than weak (B) players.

(c) With SYM, players invest more than weak (B) players under ASYM.

The first part of this result follows from the positive coefficients in Tables 5 and 4. The second and third parts are implied by a positive $\beta_{\text {strong }}$ and a positive $\beta_{S Y M}$, respectively.

The above discussion indicates that players' investments deviate from equilibrium investments of selfish players. We now check whether distributional preferences can explain our observations. More precisely, in light of the predictions we formulated in Section 4, we want to explore whether players' behavior is consistent with either inequity aversion, social welfare or competitive preferences. Table 5.1 shows frequencies of pairs of investments that were smaller, equal or larger than Nash equilibrium. We see that in all cases the majority of pairs simultaneously invests more than Nash equilibrium.

Recall from Prediction 1 that inequity averse players would not simultaneously overinvest under ASYM. The observed behavior is consistent not with inequity aversion but with social welfare preferences.

Result 3 Players' behavior is consistent with social welfare preferences, while it cannot be explained by either inequality aversion or competitive preferences. 

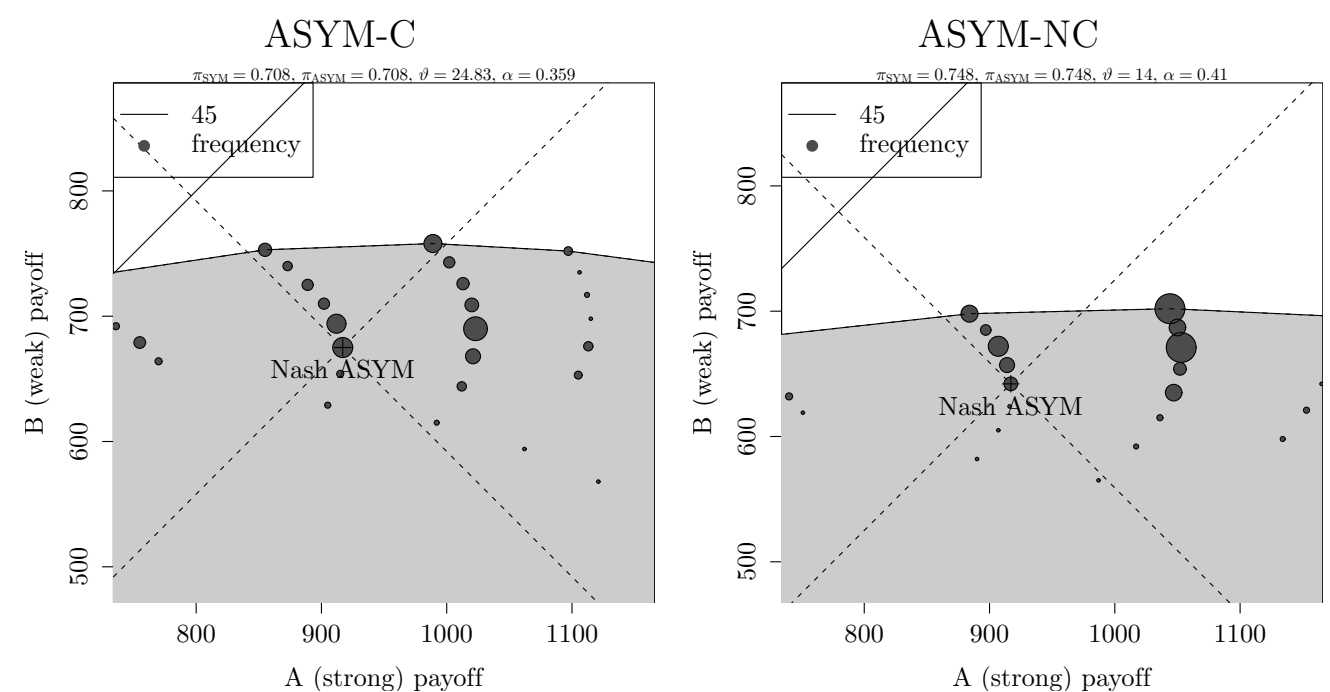

Sizes (areas) of the circles are proportional to empirical frequencies. The shaded area is the convex hull of possible payoffs.

FiguRE 7: Payoff distributions under asymmetric sharing rules

As a consequence of the simultaneous overinvestment of both players, in the majority of cases social welfare increases. Interestingly, this comes with an increase in inequality Figure 7 shows the distribution of payoffs for the weak and for the strong player in ASYM. Sizes of the circles are proportional to empirical frequencies. We clearly see that the actual allocations are typically more efficient than Nash equilibrium allocations. However, they often become even more unequal than the (already unequal) Nash equilibrium allocation. For the ASYM treatments inequality in the experiment (measured as payoff ratio) is $5.4 \%$ larger on average than inequality under the Nash equilibrium. 12 These results do support the general findings outlined in Charness and Rabin (2002).

Result 4 When asymmetric sharing rules are employed, payoff allocations are typically more efficient, but more unequal than the self-interest equilibrium allocation.

\subsection{Expectations and Behavior}

To better understand the results described above, we analyze players' expectations in the fixed contract treatments. Figures 8 and 9 show the distribution of choices and expectations for ASYM-C and SYM-C respectively. As in fig-

\footnotetext{
${ }^{12}$ This is significantly different from zero with a $p$-value of $2.5 \%$.
} 

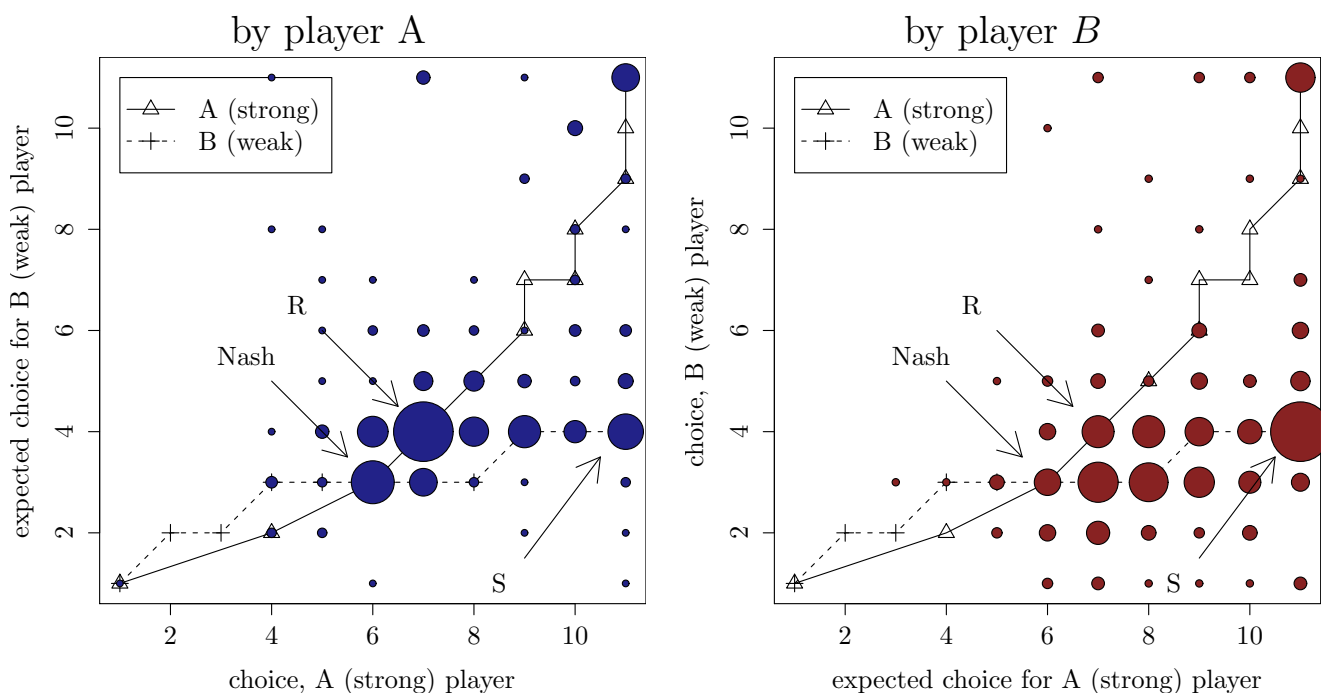

Sizes (areas) of the circles are proportional to empirical frequencies.

FiguRE 8: Distribution of choices and expectations in ASYM-C

ure 7 sizes of circles are proportional to frequencies. The figures also include the best reply functions as already shown in Figure 1.13

Let us start with the left hand graph in Figure 8. This graph shows choices and expectations of type $A$ players, i.e. players who get a share of $\pi=0.708$. With selfish players equilibrium choices and expectations would be given by the intersection of the two best reply curves, i.e. the point marked "Nash" in the graph. While some choices and expectations are consistent with this point, a peak of the distribution can be found at point $R$. This point describes a situation where a type $A$ player expects an investment of 4 by the opponent (i.e. more than equilibrium) and chooses a best reply (i.e. 7). A second peak of the distribution can be found at point $S$. Here expectations of the type $A$ player are the same as in point $R$ (a moderate overinvestment of the type $B$ player), however $A$ 's choice is full investment.

The right hand graph in Figure 8 shows choices and expectations of type $B$ players. These choices and expectations are surprisingly consistent with those of player A. The only exception is type $B$ players expects type $A$ players to invest slightly more than what type $A$ players actually do.

It is interesting to note that these expectations, and subsequent choices, are consistent with the equilibrium prediction when players display concerns for social welfare. Strong players invest well above the self-interest Nash equi-

\footnotetext{
${ }^{13}$ As best reply functions are closer to each other under no conflict, the relative figures are less instructive and we do not show them for the sake of brevity
} 

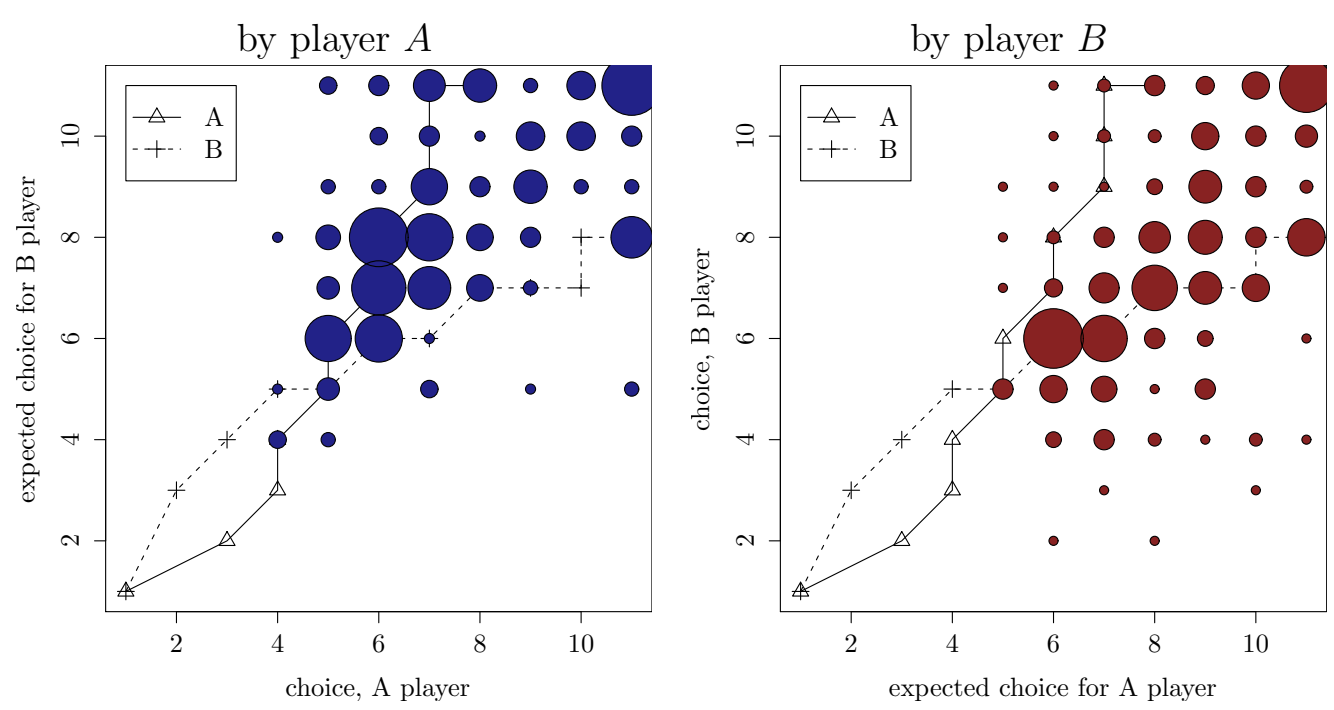

Sizes (areas) of the circles are proportional to empirical frequencies.

Figure 9: Distribution of choices and expectations in SYM-C

librium level, and expect a slight overinvestment of their weak opponents. On the other hand, weak players expect their opponents to choose investments above the self-interest Nash equilibrium, and reply by slightly overinvesting, even though not as much as their opponents.

Figure 9 refers to the symmetric contract. We can see that a large part of players expect their opponents to invest more than Nash equilibrium and best reply accordingly by overinvesting. As in the asymmetric case, this pattern is also consistent with the hypothesis that individuals display social welfare preferences.

Result 5 Players' expectations of their partners' choices are generally consistent with the actual investments undertaken. Furthermore, players' expectations, and their consequent choices, are compatible with the hypothesis of social welfare preferences.

\subsection{Flexible contracts}

The last part of the experiment is the situation FLEX where players can choose what kind of sharing rule to adopt. Figure 10 reports the distribution of votes for the symmetric contract over time, under either parameter configuration. Players are clearly guided by the rational equilibrium prediction. $B$ players, who in equilibrium benefit from the symmetric contract both in FLEX-C and FLEX-NC, almost always vote in favor of this sharing rule. 

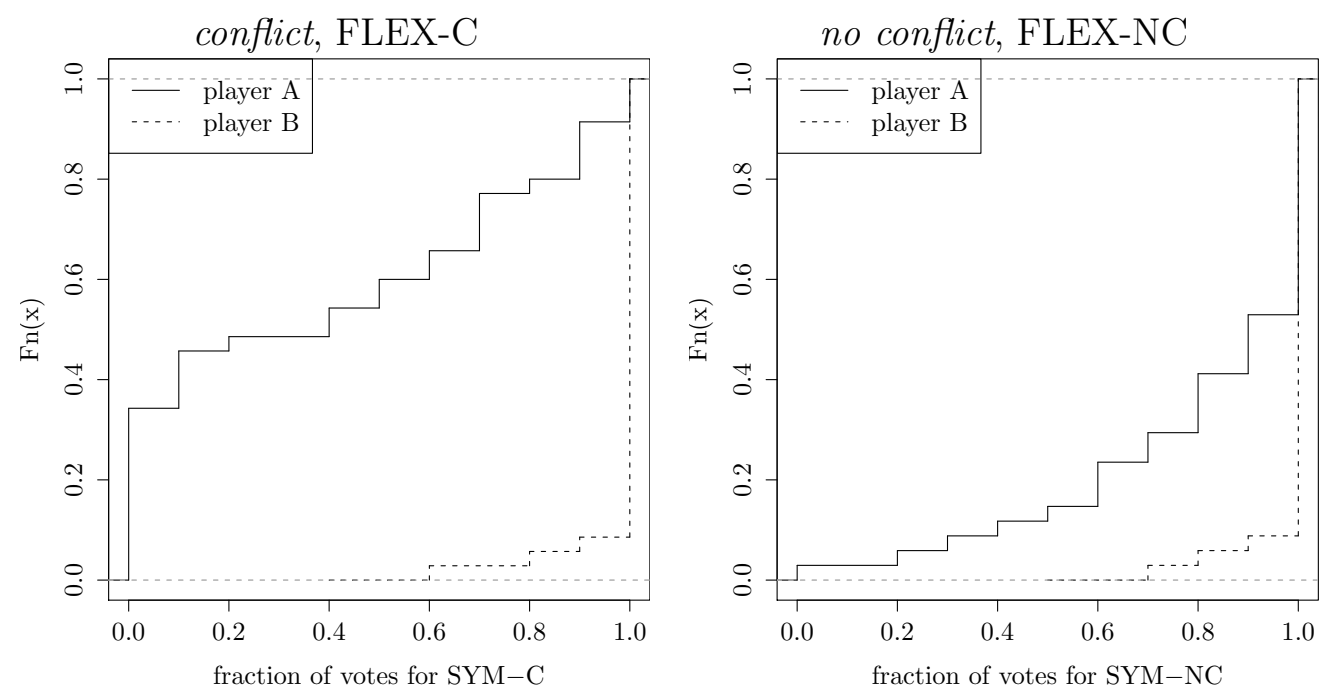

Figure 10: Fraction of votes for SYM

$A$ players, who in equilibrium benefit from the symmetric contract only in FLEX-NC, support the equal division under this configuration much more often than in FLEX-C.

Result 6 Weak players almost always vote in favor of symmetric sharing rules. Strong players agree to share power much more often in FLEX-NC than in FLEX-C. This pattern is consistent with standard game theoretical predictions.

While, theoretically, SYM yields smaller payoffs than ASYM in FLEX-C, nevertheless, about $66 \%$ of strong players vote in favor of SYM at least once. Why is this? Recall that before playing FLEX, players had experienced both SYM and ASYM. Figure 11 shows the distribution of average payoffs players experienced in these stages. In the no conflict treatment $A$ players should theoretically expect higher payoffs with SYM than with ASYM. Indeed, this is the case for $76 \%$ of all $A$ players. In the conflict treatment $A$ players should theoretically expect smaller payoffs with SYM than with ASYM (and, hence, vote against). However, $43 \%$ of the $A$ players experienced larger payoffs with SYM than with ASYM.

This is not least a consequence of the social welfare preferences exhibited by $B$ players which led to overinvestment under SYM. $A$ players, who made a good experience with SYM in the first part of the game, are likely to vote for SYM when they can. These players are willing to invest more than the 

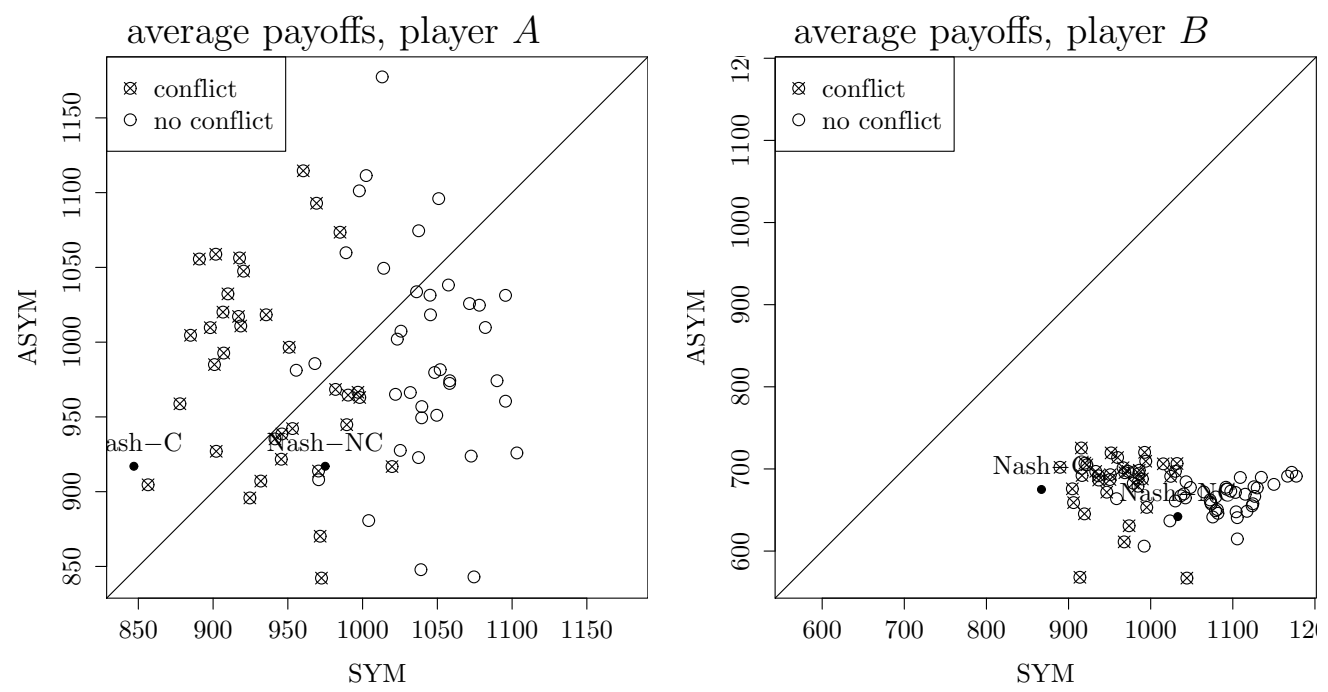

Figure 11: Average payoffs in SYM and ASYM

\begin{tabular}{l||c|c|c|c|cc|}
\hline & $\beta$ & $\sigma$ & $z$ & $p$ value & $95 \%$ conf & interval \\
\hline 1 & -1.83 & 0.939 & -1.95 & 0.0508 & -3.67 & 0.00645 \\
$r$ & 2.64 & 0.863 & 3.05 & 0.0023 & 0.945 & 4.33 \\
$d_{\text {confl. }}$ & -1.06 & 0.366 & -2.89 & 0.0038 & -1.77 & -0.342 \\
\hline
\end{tabular}

TABle 7: Mixed effects estimation of equation 12 for player $A$

rational Nash level and, at the same time, expect to be rewarded by their partners' higher investments.

To test this more formally, we estimate a mixed effects probit model.

$$
P(S Y M)=\Phi\left(\beta_{1}+\beta_{r} \cdot r+\beta_{\text {confl. }} \cdot d_{\text {confl. }}+u_{s}\right)
$$

We call $r$ the ratio of payoffs $r=\bar{\pi}_{S Y M} / \bar{\pi}_{A S Y M}$ which was experienced in the previous stages of the game. The dummy $d_{\text {confl. }}$ is one in conflict and zero in no conflict. We include a noise term for session $u_{s} . \Phi$ is the standard normal distribution. Results are shown in table 7. As we should expect the coefficient of $r$ is positive and significant: the larger the relative profits under SYM in the first stage of the game are, the higher the probability that an $A$ player votes in the FLEX stage for SYM. Also not surprising, the coefficient of $d_{\text {confl. }}$ is negative and significant: the general inclination to vote for SYM is smaller in the conflict condition.

The above interpretation is supported by the following finding. Figure 12 shows the investments of the strong player depending on the choice of contract (since almost all weak players choose the symmetric contract we 


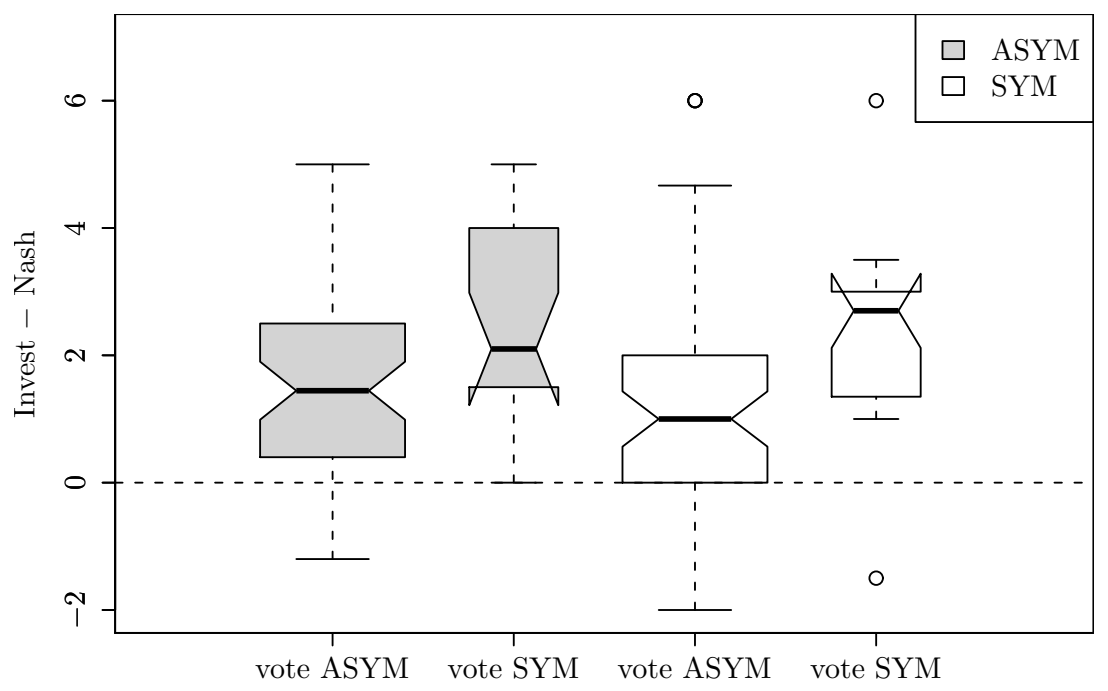

The figure shows the difference between actual and Nash investment for player $A$ depending on player A's vote and depending on the actual contract (ASYM or SYM). In this figure we pool data from conflict and no conflict. Notches indicate $95 \%$ intervals for the difference in two medians (see figure 6).

Figure 12: Investments and votes of player A

focus on player A). We see that those players $A$ who vote for a symmetric contract always invest significantly more then those who do not: investment levels are higher both under the ASYM and SYM regime.

Result 7 In FLEX-C, the majority of strong (A) players agree to give up their power at least once. Strong players who vote in favor of SYM invest more than those who vote against, both in FLEX-C and FLEX-NC.

For a formal analysis we estimate Equation 13 for the strong player (A) (for the FLEX treatment where players can choose a contract).

$$
I_{i, t}-I^{N}=\beta_{0}+\beta_{\mathrm{SYMvote}} \cdot d_{\mathrm{SYMvote}}+\beta_{S Y M} \cdot d_{S Y M}+u_{s}+u_{i j}
$$

Again we estimate a mixed effects model with a random effect for session $u_{s}$. Estimation results are shown in Tables 9 and 8 . The estimation results confirm what we see in Figure 12. Let us first look at the estimation for conflict in Table 9. As we have seen in figure 10, not all strong players cast a fair vote here. However, those how do make also significantly higher investments than those who do not.

The same holds for no conflict as shown in Table 8. There, however, the effect is much smaller and explains a smaller part of the variance. We 


\begin{tabular}{l||c|c|c|c|cc|c}
\hline & $\beta$ & $\sigma$ & $t$ & $p$ value & $95 \%$ conf & interval & pmvd \\
\hline 1 & 0.876 & 0.296 & 2.96 & 0.0032 & 0.294 & 1.46 & \\
$d_{\text {SYMvote }}$ & 1.15 & 0.162 & 7.08 & 0.0000 & 0.83 & 1.47 & 0.627 \\
$d_{S Y M}$ & 0.857 & 0.136 & 6.31 & 0.0000 & 0.591 & 1.12 & 0.373 \\
\hline
\end{tabular}

TABLE 8: Mixed effects estimation of equation 13 for player A, no conflict

\begin{tabular}{l||c|c|c|c|cc|c}
\hline & $\beta$ & $\sigma$ & $t$ & $p$ value & $95 \%$ conf & interval & pmvd \\
\hline 1 & 1.65 & 0.301 & 5.48 & 0.0000 & 1.06 & 2.24 & \\
$d_{\text {SYMvote }}$ & 0.252 & 0.139 & 1.81 & 0.0710 & -0.0215 & 0.525 & 0.495 \\
$d_{S Y M}$ & -0.668 & 0.104 & -6.45 & 0.0000 & -0.871 & -0.464 & 0.505 \\
\hline
\end{tabular}

TABLE 9: Mixed effects estimation of equation 13 for player A, conflict

should keep in mind that in no conflict it is in the own interest of the strong players to move to a power sharing rule. Casting a fair vote is not a sign of a particularly other regarding preference. Hence, there is no reason to expect a specific altruistic behavior of these players.

\section{Conclusion}

The seminal works of Grossman and Hart (1986) and Hart and Moore (1990) have shed light on the central role played by property rights when contracts are incomplete, describing their effect on parties' incentives to undertake relationship-specific investments. Property rights can be looked at as an abstract exemplification of the way power is allocated between parties. Indeed, partnerships can be characterized by their power structure, and it is very common to observe partnerships in which one party holds more power than another. In this paper, we explored experimentally the extent to which different power structures affect incentives to make relationship-specific investments when contracts are incomplete. Despite the great attention devoted to incomplete contracts in recent years, only a limited amount of experimental evidence has been produced so far. Furthermore, to the best of our knowledge, our study represents the first attempt to analyze the effect of power structure in incomplete contracts.

We considered two equally productive players who simultaneously decide how much to invest into a joint production process. We first analyzed the 
players' investment behavior when the power structure is exogenously imposed. As the players' productivity is the same, theory predicts that total investments would be lower in the presence of power imbalances and higher when power is equally shared. This result is confirmed by our experimental evidence. However, we observed significant overinvestment, with respect to the self-interest Nash prediction, both under symmetric and asymmetric conditions. With asymmetric sharing rules both types of players, even the weak one, invest more than predicted by Nash equilibrium. Nonetheless, overinvestment is higher among strong players. To better understand these results, we examined the players' expectations of their partners' choices. These are surprisingly consistent with the actual investments undertaken.

As standard game theoretical analysis fails to explain the players' investment choices, we explored the predictions and implications of different behavioral theories, namely: inequity aversion, social welfare and competitive preferences. Differently from several other experiments, our design allows us to disentangle the effect that different social preferences have over individual investment behavior. We showed that players' behavior is consistent with the hypothesis that individuals are concerned with social efficiency. Interestingly, the player's choices cannot be explained by either inequity aversion or competitive preferences. This is an important result, which confirms the main findings of Charness and Rabin (2002).

Finally we examined situations where the power structure is flexible. Starting from a condition of asymmetry, the two players can agree to switch to a symmetric sharing rule. If they disagree, the asymmetric contract is applied. We analyzed this type of flexible structure under two different conditions. In one, both players should rationally (and selfishly) agree to share power equally. In the other, strong players should not give up power in equilibrium. This prediction is qualitatively supported by our data. Indeed, strong players choose to give up power much more often when it is rational to do so. Nevertheless, we observe power-sharing agreements even when standard game theory predicts that the strong player should retain her power. This finding can again be explained assuming that individuals display concerns for social welfare. 


\section{References}

Adelman, Jeremy (1994), Frontier Development: Land, Labour, and Capital on the Wheatlands of Argentina and Canada, 1890-1914. Oxford University Press.

Bolton, Gary E. and Axel Ockenfels (2000), "Erc: A theory of equity, reciprocity, and competition." The American Economic Review, 90, 166-193, URL.

Chambers, John M., William S. Cleveland, Beat Kleiner, and Paul A. Tukey (1983), Graphical Methods for Data Analysis. Wadsworth \& Brooks.

Charness, Gary and Brit Grosskopf (2001), "Relative payoffs and happiness: an experimental study." Journal of Economic Behavior \& Organization, $45,301-328$, URL.

Charness, Gary and Matthew Rabin (2002), "Understanding Social Preferences with Simple Tests." Quarterly Journal of Economics, 117, 817-869, URL.

Corry, Stephen (1993), "The rainforest harvest: Who reaps the benefit?" Ecologist, 23, 148-153.

Engelmann, Dirk and Martin Strobel (2004), "Inequality aversion, efficiency, and maximin preferences in simple distribution experiments." American Economic Review, 94, 857-869, URL.

Fehr, Ernst, Oliver Hart, and Christian Zehnder (2008a), "Contracts as Reference Points - Experimental Evidence." Unpublished Manuscript, URL.

Fehr, Ernst, Erich Kirchler, Andreas Weichbold, and Simon Gächter (1998), "When social norms overpower competition: Gift exchange in experimental labor markets." Journal of Labor Economics, 16, 324-351.

Fehr, Ernst, Susanne Kremhelmer, and Klaus M. Schmidt (2008b), "Fairness and the Optimal Allocation of Property Rights." Economic Journal, 118, $1262-1284$, URL.

Fehr, Ernst and Klaus M. Schmidt (1999), "A theory of fairness, competition, and cooperation." The Quarterly Journal of Economics, 114, 817-868.

Feldman, Barry (2005), "Relative importance and value." Technical report, Kellstadt Graduate School of Business, URL.

Fischbacher, Urs (2007), "z-tree: Zurich toolbox for ready-made economic experiments." Experimental Economics, 10, 171-178, URL. 
Gantner, Anita, Werner Güth, and Manfred Königstein (2001), "Equitable choices in bargaining games with joint production." Journal of Economic Behavior and Organization, 46, 209-225.

Greiner, Ben (2004), "An online recruitment system for economic experiments." In Forschung und wissenschaftliches Rechnen (Kurt Kremer and Volker Macho, eds.), volume 63, of GWDG Bericht, 79-93, Ges. für Wiss. Datenverarbeitung, Göttingen.

Grömping, Ulrike (2007), "Estimators of relative importance in linear regression based on variance decomposition." The American Statistician, 61, 139-147, URL.

Grossman, Sanford J. and Oliver D. Hart (1986), "The Costs and Benefits of Ownership: A Theory of Vertical and Lateral Integration." The Journal of Political Economy, 94, 691-719.

Hacket, Steven C. (1994), "Is relational exchange possible in the absence of reputations and repeated contact." The Journal of Law, Economics and Organization, 10, 360-389, URL.

Hart, Oliver (1995), Firms, contracts, and financial structure. Oxford: Clarendon Press.

Hart, Oliver (2008), "Reference Points and the Theory of the Firm." Economica, 75, 404-411, URL.

Hart, Oliver and John Moore (1990), "Property Rights and the Nature of the Firm." Journal of Political Economy, 98, 1119-1158.

Hart, Oliver and John Moore (2008), "Contracts as Reference Points." Quarterly Journal of Economics, 123, 1-48, URL.

Isaac, R. Mark and James M. Walker (1998), "Nash as an Organizing Principle in the Voluntary Provision of Public Goods: Experimental Evidence." Experimental Economics, 1, 191-206.

Klein, Benjamin, Robert G. Crawford, and Armen A. Alchian (1978), "Vertical Integration, Appropriable Rents, and the Competitive Contracting Process." The Journal of Law and Economics, 21, 297-326, URL.

Kritikos, Alexander and Friedel Bolle (2001), "Distributional concerns: equity- or efficiency-oriented?" Economics Letters, 73, 333-338, URL.

Laury, Susan K. and Charles A. Holt (2008), "Voluntray provision of public goods: Experimental results with interior nash equilibria." In The Handbook of Experimental Economics Results (C.R. Plott and V.R. Smith, eds.), Elsevier. 
Mayers, James and Sonja Vermeulen (2002), "Company-community forestry partnerships: From raw deals to mutual gains? instruments for sustainable private sector forestry series." Technical report, London: International Institute for Environment and Development (IIED), URL.

Morsello, Carla (2006), "Company-community non-timber forest product deals in the Brazilian Amazon: A review of opportunities and problems." Forest Policy and Economics, 8, 485-494, URL.

Morsello, Carla and W. Neil Adger (2006), "Do partnerhships between large corporations and amazonian indigenous groups help or hinder communities and forests?" In Partnerships in Sustainable Forest Resource Management: Learning from Latin America (M. A. Ros-Tonen, ed.), Brill Academic Publishers, URL.

Oosterbeek, Hessel, Joep Sonnemans, and Susan van Velzen (2003), "The need for marriage contracts: An experimental study." Journal of Population Economics, 16, 431-453, URL.

Tomlinson, B.R. (1996), The Economy of Modern India, 1860-1970. Cambridge University Press, URL.

Turner, Terence (1995), "Neoliberal Ecopolitics and Indigenous Peoples: The Kayapó, The "Rainforest Harvest", and The Body Shop." Yale F \& ES Bulletin, 98, 113-127, URL.

\section{A Technical Appendix: Behavioral Predic- tions}

\section{A.1 Proof of Proposition 1}

If players exhibit self-interested preferences, then each player $i$ 's decision problem is simply to choose $I_{i}$ to maximize her material payoff

$$
U_{i}\left(I_{A}, I_{B}\right)=M-I_{i}+\pi_{i} \vartheta\left(I_{i} I_{j}\right)^{\alpha}
$$

where $i \in\{A, B\}$ and $i \neq j$. The Nash equilibrium investment levels of the self-interest model, $I_{A}^{s}$ and $I_{B}^{s}$, are the solutions to the first-order conditions

$$
\pi \alpha S I_{A}^{\alpha-1} I_{B}^{\alpha}=1 \quad \text { and } \quad(1-\pi) \alpha S I_{A}^{\alpha} I_{B}^{\alpha-1}=1
$$

The proposition follows immediately after solving these two equations for $I_{A}$ and $I_{B}$. 


\section{A.2 Proof of Proposition 2}

Now consider the two players' optimal choice of $I_{A}$ and $I_{B}$ when they have social preferences, i.e., when their payoffs are given by

$$
V_{A}\left(I_{A}, I_{B}\right)=(\rho \cdot r+\sigma \cdot s) \cdot U_{B}\left(I_{A}, I_{B}\right)+(1-\rho \cdot r-\sigma \cdot s) \cdot U_{A}\left(I_{A}, I_{B}\right)
$$

and

$$
V_{B}\left(I_{A}, I_{B}\right)=(\rho \cdot s+\sigma \cdot r) \cdot U_{A}\left(I_{A}, I_{B}\right)+(1-\rho \cdot s-\sigma \cdot r) \cdot U_{B}\left(I_{A}, I_{B}\right)
$$

where $r=1$ and $s=0$ if $U_{A}(\cdot)>U_{B}(\cdot), r=0$ and $s=1$ if $U_{A}(\cdot)<U_{A}(\cdot)$, and $r=0$ and $s=0$ if $U_{A}(\cdot)=U_{A}(\cdot)$. We do this in detail for the case where any asymmetry in sharing rule favors player $A$ and discriminates against player $B$, i.e., we focus on parameter values satisfying $\pi \geq 1 / 2$. We begin with player $A$. Her best response function is shown in the first panel of Figure 13 below. There, $\hat{I}_{A}\left(I_{B}\right)$ is the value of $I_{A}$ for which the material payoffs of the two players are equal, i.e., $\hat{I}_{A}\left(I_{B}\right)$ implicitly solves

$$
\underbrace{M-I_{A}+\pi \vartheta\left(I_{A} I_{B}\right)^{\alpha}}_{U_{A}\left(I_{A}, I_{B}\right)}=\underbrace{M-I_{B}+(1-\pi) \vartheta\left(I_{A} I_{B}\right)^{\alpha}}_{U_{B}\left(I_{A}, I_{B}\right)}
$$

Notice that $U_{A}(\cdot)>[<] U_{B}(\cdot)$ when $I_{A}<[>] \hat{I}_{A}\left(I_{B}\right)$.

Also, $I_{A}^{0}\left(I_{B}\right)=\arg \max \sigma U_{B}\left(I_{A}, I_{B}\right)+(1-\sigma) U_{A}\left(I_{A}, I_{B}\right)$, i.e.,

$$
I_{A}^{0}\left(I_{B}\right)=\left[\gamma_{A} I_{B}^{\alpha}\right]^{\frac{1}{1-\alpha}} \quad \text { where } \quad \gamma_{A}=\frac{(1-\sigma) \pi+\sigma(1-\pi)}{1-\sigma},
$$

and $I_{A}^{1}\left(I_{B}\right)=\arg \max \rho U_{B}\left(I_{A}, I_{B}\right)+(1-\rho) U_{A}\left(I_{A}, I_{B}\right)$, i.e.,

$$
I_{A}^{1}\left(I_{B}\right)=\left[\kappa_{A} I_{B}^{\alpha}\right]^{\frac{1}{1-\alpha}} \quad \text { where } \quad \kappa_{A}=\frac{(1-\rho) \pi+\rho(1-\pi)}{1-\rho} .
$$

The intersection between $\hat{I}_{A}\left(I_{B}\right)$ and $I_{A}^{0}\left(I_{B}\right)$ occurs at the point where

$$
I_{A}^{\prime}=\left[\alpha \vartheta\left(\gamma_{A}\right)^{1-\alpha}\left(\gamma_{A}-\varepsilon\right)^{\alpha}\right]^{\frac{1}{1-2 \alpha}} \quad \text { and } \quad I_{B}^{\prime}=\left[\alpha \vartheta\left(\gamma_{A}\right)^{\alpha}\left(\gamma_{A}-\varepsilon\right)^{1-\alpha}\right]^{\frac{1}{1-2 \alpha}} \text {. }
$$

where $\epsilon=(2 \pi-1) / \alpha$. The intersection between $\hat{I}_{A}\left(I_{B}\right)$ and $I_{A}^{1}\left(I_{B}\right)$ occurs at the point where

$$
\bar{I}_{A}=\left[\alpha \vartheta\left(\kappa_{A}\right)^{1-\alpha}\left(\kappa_{A}-\varepsilon\right)^{\alpha}\right]^{\frac{1}{1-2 \alpha}} \quad \text { and } \quad \bar{I}_{B}=\left[\alpha \vartheta\left(\kappa_{A}\right)^{\alpha}\left(\kappa_{A}-\varepsilon\right)^{1-\alpha}\right]^{\frac{1}{1-2 \alpha}}
$$

The bottom panel of Figure 13 shows player $B$ 's best response function. As before, $\hat{I}_{B}\left(I_{A}\right)$ is the value of $I_{B}$ for which the material payoffs of the two players are equal, i.e., $\hat{I}_{B}\left(I_{A}\right)$ implicitly solves $M-I_{A}+\pi \vartheta\left(I_{A} I_{B}\right)^{\alpha}=$ $M-I_{B}+(1-\pi) \vartheta\left(I_{A} I_{B}\right)^{\alpha}$, and $U_{A}(\cdot)>[<] U_{B}(\cdot)$ when $I_{A}<[>] \hat{I}_{A}\left(I_{B}\right)$. Also, 


$$
\begin{aligned}
I_{B}^{0}\left(I_{A}\right)= & \arg \max \sigma U_{A}\left(I_{A}, I_{B}\right)+(1-\sigma) U_{B}\left(I_{A}, I_{B}\right), \text { i.e., } \\
& I_{B}^{0}\left(I_{A}\right)=\left[\gamma_{B} I_{A}^{\alpha}\right]^{\frac{1}{1-\alpha}} \quad \text { where } \quad \gamma_{B}=\frac{(1-\sigma)(1-\pi)+\sigma \pi}{1-\sigma},
\end{aligned}
$$

and $I_{B}^{1}\left(I_{A}\right)=\arg \max \rho U_{A}\left(I_{A}, I_{B}\right)+(1-\rho) U_{B}\left(I_{A}, I_{B}\right)$, i.e.,

$$
I_{B}^{1}\left(I_{A}\right)=\left[\kappa_{B} I_{A}^{\alpha}\right]^{\frac{1}{1-\alpha}} \quad \text { where } \quad \kappa_{B}=\frac{(1-\rho)(1-\pi)+\rho \pi}{1-\rho} .
$$

The intersection between $\hat{I}_{B}\left(I_{A}\right)$ and $I_{B}^{0}\left(I_{A}\right)$ occurs at the point where

$$
\underline{I}_{A}=\left[\alpha \vartheta\left(\gamma_{B}+\varepsilon\right)^{1-\alpha}\left(\gamma_{B}\right)^{\alpha}\right]^{\frac{1}{1-2 \alpha}} \quad \text { and } \quad \underline{I}_{B}=\left[\alpha \vartheta\left(\gamma_{B}+\varepsilon\right)^{\alpha}\left(\gamma_{B}\right)^{1-\alpha}\right]^{\frac{1}{1-2 \alpha}}
$$

The intersection between $\hat{I}_{A}\left(I_{B}\right)$ and $I_{A}^{1}\left(I_{B}\right)$ occurs at the point where

$$
I_{A}^{\prime \prime}=\left[\alpha \vartheta\left(\kappa_{B}+\varepsilon\right)^{1-\alpha}\left(\kappa_{B}\right)^{\alpha}\right]^{\frac{1}{1-2 \alpha}} \quad \text { and } \quad I_{B}^{\prime \prime}=\left[\alpha \vartheta\left(\kappa_{B}+\varepsilon\right)^{\alpha}\left(\kappa_{B}\right)^{1-\alpha}\right]^{\frac{1}{1-2 \alpha}}
$$

We now note that for every player $i, i \in\{A, B\}$,

$$
\underline{I}_{i} \geq I_{i}^{\prime} \quad \text { and } \quad \bar{I}_{i} \leq I_{i}^{\prime \prime} \quad \text { for all } \quad \pi \geq \frac{1}{2}
$$

Moreover, it is readily checked that

$$
\underline{I}_{i} \lesseqgtr \bar{I}_{i} \quad \text { if and only if } \pi \lesseqgtr \bar{\pi},
$$

where

$$
\bar{\pi}=\frac{\mu}{1+\mu} \quad \text { where } \quad \mu=\frac{(1-\sigma)[(1-\alpha)(1-\rho)+\rho \alpha]}{(1-\rho)[(1-\alpha)((1-\sigma)+\sigma \alpha]}>1
$$

With these preliminaries in hand, we now derive all possible equilibrium equilibrium configurations of the investment game. Consider first the case where

$$
\gamma_{B}=\frac{(1-\sigma)(1-\pi)+\sigma \pi}{1-\sigma}>0 \quad \text { or equivalently } \quad \sigma>-\frac{1-\pi}{2 \pi-1} \equiv \bar{\sigma} .
$$

It should be clear from Figure 13 that in the case under consideration, there are two kinds of possible equilibrium configurations in the investment game. The first, illustrated in the top panel of Figure 14, occurs when $\pi \in[1 / 2, \bar{\pi})$, i.e., when the sharing rule used to divide output is sufficiently close to onehalf. Then, $\underline{I}_{i}<\bar{I}_{i}$ for every player $i$, and hence there exists a closed set of Nash equilibria in pure strategies. All equilibria are located on the line $\hat{I}_{B}\left(I_{A}\right)$ where the material payoffs of the two players are equal, i.e., in every equilibrium the investments chosen by $A$ and $B$ lead to an equalization of their material payoffs. Clearly, the equilibrium with the highest aggregate 
investment is determined by the intersection of $\hat{I}_{B}\left(I_{A}\right)$ and $I_{A}^{1}\left(I_{B}\right)$ and therefore occurs at the point where $\left(I_{A}, I_{B}\right)=\left(\bar{I}_{A}, \bar{I}_{B}\right)$. The equilibrium with the lowest aggregate investment is determined by intersection of $\hat{I}_{B}\left(I_{A}\right)$ and $I_{B}^{0}\left(I_{A}\right)$ and therefore occurs at the point where $\left(I_{A}, I_{B}\right)=\left(\underline{I}_{A}, \underline{I}_{B}\right)$.

The second kind of equilibrium, shown in the bottom panel of Figure 14, occurs when $\pi \in[\bar{\pi}, 1)$, i.e., when the sharing rule used to divide output is sufficiently bounded away from one-half. Then, $\underline{I}_{i} \geq \bar{I}_{i}$ for every player $i$. In this case, there exists a unique interior pure-strategy equilibrium that has a particularly simple form: it is determined by the intersection of $I_{B}^{0}\left(I_{A}\right)$ and $I_{A}^{1}\left(I_{0}\right)$ and therefore given by

$$
I_{A}^{*}=\left[\alpha \vartheta\left(\kappa_{A}\right)^{1-\alpha}\left(\gamma_{B}\right)^{\alpha}\right]^{\frac{1}{1-2 \alpha}} \quad \text { and } \quad I_{B}^{*}=\left[\alpha \vartheta\left(\kappa_{A}\right)^{\alpha}\left(\gamma_{B}\right)^{1-\alpha}\right]^{\frac{1}{1-2 \alpha}} .
$$

Consider now the case where

$$
\sigma \leq-\frac{1-\pi}{2 \pi-1} \equiv \bar{\sigma}
$$

It is readily checked that in this case $\gamma_{B} \leq 0$ and $\gamma_{A}-\epsilon \leq 0$. As a result, for every player $i, \underline{I}_{i}=0$ and $I_{i}^{\prime}=0$. The best response functions of player $A$ is now $\hat{I}_{A}\left(I_{B}\right)$ if $I_{A} \leq \bar{I}_{A}$ and $I_{A}^{1}\left(I_{B}\right)$ if $I_{A}>\bar{I}_{A}$. The best response function of player $B$ is $\hat{I}_{B}\left(I_{A}\right)$ if $I_{B} \leq I_{B}^{\prime \prime}$ and $I_{B}^{1}\left(I_{A}\right)$ if $I_{B}>I_{B}^{\prime \prime}$. It should now be clear that, irrespective of whether $\pi \in[1 / 2, \bar{\pi})$ or $\pi \in[\bar{\pi}, 1)$, there now exists a closed set of equilibria in pure strategies (see Figure 15). The equilibrium with the highest aggregate investment is determined by the intersection of $\hat{I}_{B}\left(I_{A}\right)$ and $I_{A}^{1}\left(I_{B}\right)$ and therefore occurs at the point where $\left(I_{A}, I_{B}\right)=\left(\bar{I}_{A}, \bar{I}_{B}\right)$. The equilibrium with the lowest aggregate investment now occurs at the point where $\left(I_{A}, I_{B}\right)=(0,0)$.

So, to summarize, the investment game is not always well behaved; we cannot rule out multiple equilibria when the sharing rule used to divide output is close to one-half. However, it is nevertheless possible to generate behavioral predictions, conditional on the parameter configurations used in the experiment.

\section{A.3 Proof of Prediction 1}

This result contrasts the investment incentives of self-interested players with those of individuals who have social preferences under the assumption that the sharing rule used to divide output is asymmetric $(\pi=0.708$ in ASYM-C and $\pi=0.748$ in ASYM-NC). We now provide a proof of this result. In so doing, we focus purely on the parameter configurations used in the experiment. Moreover, we restrict our attention to parameter values satisfying and $\rho \leq 1 / 2$.

- Treatment ASYM-C $(\pi=0.708, \alpha=0.359, \vartheta=24.83)$ : For the parameter values under consideration, the equilibrium investment levels 
of self-interested individuals are given by

$$
I_{A}^{s}=222.62 \quad \text { and } \quad I_{B}^{s}=91.82
$$

Suppose now that individuals exhibit distributional preferences. Consider first the case where

$$
\sigma>-\frac{1-\pi}{2 \pi-1} \equiv \bar{\sigma} \quad \Rightarrow \quad \sigma>-0.702
$$

The condition for the existence of a unique interior pure-strategy equilibrium is

$$
0.708 \geq \frac{-(0.641-0.282 \rho)(1-\sigma)}{0.923 \rho-0.564 \rho \sigma-1.282+0.923 \sigma} \equiv \bar{\pi},
$$

which, given $\pi=0.708$, is satisfied for all $\sigma>-0.702$ and $\rho \leq 0.5$. In the unique interior pure-strategy equilibrium, the equilibrium investment levels are given by

$$
\begin{aligned}
& I_{A}^{*}=0.026\left[\left(\frac{0.708-0.416 \rho}{1-\rho}\right)^{0.641}\left(\frac{0.292+0.416 \sigma}{1-\sigma}\right)^{0.359}\right]^{3.546} \\
& I_{B}^{*}=0.026\left[\left(\frac{0.708-0.416 \rho}{1-\rho}\right)^{0.359}\left(\frac{0.292+0.416 \sigma}{1-\sigma}\right)^{0.641}\right]^{3.546}
\end{aligned}
$$

Comparing (33) and (36), it is now readily checked that

- if individuals exhibit competitive preferences $(\sigma \leq \rho \leq 0)$ or inequity aversion $(\sigma<-\rho<0)$, then there is simultaneous underinvestment in equilibrium, i.e., $I_{A}^{*}<I_{A}^{s}$ and $I_{B}^{*}<I_{B}^{s}$;

- if individuals are concerned about social welfare $(\sigma \leq \rho \leq 0)$, then there is simultaneous overinvestment in equilibrium, i.e., $I_{A}^{*}>I_{A}^{s}$ and $I_{B}^{*}>I_{B}^{s}$.

Consider now the case where

$$
\sigma \leq-\frac{1-\pi}{2 \pi-1} \equiv \bar{\sigma} \quad \Rightarrow \quad \sigma \leq-0.702
$$

This case is limited to competitive preferences $(\sigma \leq \rho \leq 0)$ and inequity aversion $(\sigma<-\rho<0)$. For the parameter values under consideration, there exists a unique pure strategy equilibrium in which both parties invest zero, 14 Thus, our previous observation that competitive pref-

\footnotetext{
${ }^{14}$ To see this, recall that, when $\sigma \leq \bar{\sigma}$, there generally exists a closed set of purestrategy equilibria (see Figure 15). The equilibrium with the highest aggregate investments occurs where $\left(I_{A}, I_{B}\right)=\left(\bar{I}_{A}, \bar{I}_{B}\right)$. It is readily checked that, for the parameter values under consideration, $\left(\bar{I}_{A}, \bar{I}_{B}\right)=(0,0)$. Hence both parties will choose zero investments in
} 
erences or inequity aversion lead to simultaneous underinvestment in equilibrium continues to hold.

- Treatment ASYM-NC $(\pi=0.748, \alpha=0.41, \vartheta=14)$ : For the parameter values under consideration, the equilibrium investment levels of self-interested individuals are given by

$$
I_{A}^{s}=275.03 \quad \text { and } \quad I_{B}^{s}=92.66
$$

Suppose now that individuals exhibit distributional preferences. Consider first the case where

$$
\sigma>-\frac{1-\pi}{2 \pi-1} \equiv \bar{\sigma} \quad \Rightarrow \quad \sigma>-0.508
$$

The condition for the existence of a unique interior pure-strategy equilibrium is

$$
0.748 \geq \frac{-(0.59-0.18 \rho)(1-\sigma)}{0.77 \rho-0.36 \rho \sigma-1.18+0.77 \sigma} \equiv \bar{\pi}
$$

which, given $\pi=0.748$, is satisfied for all $\sigma>-0.508$ and $\rho \leq 0.5$. In the unique interior pure-strategy equilibrium, the equilibrium investment levels are given by

$$
\begin{aligned}
& I_{A}^{*}=16450.43\left[\left(\frac{0.748-0.496 \rho}{1-\rho}\right)^{0.59}\left(\frac{0.252+0.496 \sigma}{1-\sigma}\right)^{0.41}\right]^{1.273} \\
& I_{B}^{*}=16450.43\left[\left(\frac{0.748-0.496 \rho}{1-\rho}\right)^{0.41}\left(\frac{0.252+0.496 \sigma}{1-\sigma}\right)^{0.59}\right]^{1.273}
\end{aligned}
$$

Comparing (38) and (41), it is now readily checked that

- if individuals exhibit competitive preferences $(\sigma \leq \rho \leq 0)$ or inequity aversion $(\sigma<-\rho<0)$, then there is simultaneous underinvestment in equilibrium, i.e., $I_{A}^{*}<I_{A}^{s}$ and $I_{B}^{*}<I_{B}^{s}$;

- if individuals are concerned about social welfare $(\sigma \leq \rho \leq 0)$, then there is simultaneous overinvestment in equilibrium, i.e., $I_{A}^{*}>I_{A}^{s}$ and $I_{B}^{*}>I_{B}^{s}$.

Consider now the case where

$$
\sigma \leq-\frac{1-\pi}{2 \pi-1} \equiv \bar{\sigma} \quad \Rightarrow \quad \sigma \leq-0.702
$$

This case only corresponds to competitive preferences $(\sigma \leq \rho \leq 0)$

equilibrium. 
or inequity aversion $(\sigma<-\rho<0)$. As in ASYM-C, for the parameter values under consideration, there now exists a unique pure strategy equilibrium in which both parties invest zero. Thus, our previous observation that competitive preferences or inequity aversion lead to simultaneous underinvestment in equilibrium continues to hold.

\section{A.4 Proof of Prediction 2}

This result contrasts the investment incentives of self-interested players with those of individuals who have social preferences under the assumption that the sharing rule used to divide output is symmetric $(\pi=0.491$ in SYM-C and $\pi=0.483$ in SYM-NC). We now provide a proof of this result. As before, we restrict our attention to parameter values satisfying and $\rho \leq 1 / 2$.

- Treatment SYM-C $(\pi=0.491, \alpha=0.359, \vartheta=24.83)$ : For the parameter values under consideration, the equilibrium investment levels of self-interested individuals are given by

$$
I_{A}^{s}=196.56 \quad \text { and } \quad I_{B}^{s}=203.77
$$

Suppose now that individuals exhibit distributional preferences. Consider first parameter values for which a unique interior pure-strategy equilibrium exists:

$$
\sigma>-\frac{\pi}{1-2 \pi} \equiv \bar{\sigma} \quad \Rightarrow \quad \sigma>-27.28
$$

and

$$
0.491 \leq \frac{(-0.641-0.282 \sigma)(1-\rho)}{-1.282+0.923 \sigma+0.923 \rho-0.564 \rho \sigma} \equiv 1-\hat{\pi}
$$

In the unique interior pure-strategy equilibrium, the equilibrium investment levels are given by

$$
\begin{aligned}
& I_{A}^{*}=2339.09\left[\left(\frac{0.509-0.018 \rho}{1-\rho}\right)^{0.359}\left(\frac{0.491+0.018 \sigma}{1-\sigma}\right){ }^{0.641}\right]^{3.546} \\
& I_{B}^{*}=2339.09\left[\left(\frac{0.509-0.018 \sigma}{1-\sigma}\right)^{0.359}\left(\frac{0.491+0.018 \rho}{1-\rho}\right)^{0.641}\right]^{3.546}
\end{aligned}
$$

Comparing (43) and (46), it is now readily checked that, when (44) and (45) are satisfied, then

- if individuals exhibit competitive preferences $(\sigma \leq \rho \leq 0)$, then there is simultaneous underinvestment in equilibrium, i.e., $I_{A}^{*}<I_{A}^{s}$ and $I_{B}^{*}<I_{B}^{s}$; 
- if individuals exhibit inequity aversion $(\sigma \leq-\rho \leq 0)$, then there are two possible equilibrium outcomes. In the first, there is simultaneous underinvestment in equilibrium, i.e., $I_{A}^{*}<I_{A}^{s}$ and $I_{B}^{*}<I_{B}^{s}$. In the second, player $B$ overinvests while player $A$ underinvests in equilibrium, i.e., $I_{A}^{*}<I_{A}^{s}$ and $I_{B}^{*}>I_{B}^{s}$.

- if individuals are concerned about social welfare $(\sigma \leq \rho \leq 0)$, then there is simultaneous overinvestment in equilibrium, i.e., $I_{A}^{*}>I_{A}^{S}$ and $I_{B}^{*}>I_{B}^{s}$.

Consider next the case in which

$$
0.491>\frac{(-0.641-0.282 \sigma)(1-\rho)}{-1.282+0.923 \sigma+0.923 \rho-0.564 \rho \sigma} \equiv 1-\hat{\pi}
$$

In this case, there exists a closed set of pure strategy equilibria. In the equilibrium with the highest aggregate investments the players' investment levels are given by

$$
\begin{aligned}
& I_{A}^{\prime \prime}=2339.09\left[\left(\frac{0.509-0.018 \rho}{1-\rho}\right)^{0.359}\left(\frac{0.509-0.018 \rho}{1-\rho}-0.05\right)^{0.641}\right]^{3.546} \\
& I_{B}^{\prime \prime}=2339.09\left[\left(\frac{0.509-0.018 \rho}{1-\rho}-0.05\right)^{0.359}\left(\frac{0.509-0.018 \rho}{1-\rho}\right)^{0.641}\right]^{3.546}
\end{aligned}
$$

In the equilibrium with the lowest aggregate investments the players' investment levels are given by

$$
\begin{aligned}
& I_{A}^{\prime}=2339.09\left[\left(\frac{0.491+0.018 \sigma}{1-\sigma}+0.05\right)^{0.359}\left(\frac{0.491+0.018 \sigma}{1-\sigma}\right)^{0.641}\right]^{3.546} \\
& I_{B}^{\prime}=2339.09\left[\left(\frac{0.491+0.018 \sigma}{1-\sigma}\right)^{0.359}\left(\frac{0.491+0.018 \rho}{1-\rho}+0.05\right)^{0.641}\right]^{3.546}
\end{aligned}
$$

Comparing (43) with (48) and (49) respectively, it is now readily checked that, when (47) is satisfied, then

- if individuals exhibit competitive preferences $(\sigma \leq \rho \leq 0)$, then there is simultaneous underinvestment both in the equilibrium with the highest aggregate investment $\left(I_{A}^{\prime \prime}<I_{A}^{s}\right.$ and $\left.I_{B}^{\prime \prime}<I_{B}^{s}\right)$ and in the equilibrium with lowest aggregate investment $\left(I_{A}^{\prime}<I_{A}^{s}\right.$ and $\left.I_{B}^{\prime}<I_{B}^{s}\right)$.

- if individuals exhibit inequity aversion $(\sigma \leq-\rho \leq 0)$, then there is simultaneous overinvestment in the equilibrium with the highest aggregate investment $\left(I_{A}^{\prime \prime}>I_{A}^{s}\right.$ and $\left.I_{B}^{\prime \prime}>I_{B}^{s}\right)$ and simultaneous 
underinvestment in the equilibrium with lowest aggregate investment $\left(I_{A}^{\prime}<I_{A}^{s}\right.$ and $\left.I_{B}^{\prime}<I_{B}^{s}\right)$.

- if individuals are concerned about social welfare $(\sigma \leq \rho \leq 0)$, then there is simultaneous overinvestment both in the equilibrium with the highest aggregate investment $\left(\bar{I}_{A}>I_{A}^{s}\right.$ and $\left.\bar{I}_{B}>I_{B}^{s}\right)$ and in the equilibrium with lowest aggregate investment $\left(\underline{I}_{A}>I_{A}^{s}\right.$ and $\left.\underline{I}_{B}>I_{B}^{s}\right)$.

- Treatment SYM-NC $(\pi=0.483, \alpha=0.41, \vartheta=14.00)$ : For the parameter values under consideration, the equilibrium investment levels of self-interested individuals are given by

$$
I_{A}^{s}=336.99 \text { and } \quad I_{B}^{s}=360.72
$$

Suppose now that individuals exhibit distributional preferences. Consider first parameter values for which a unique interior pure-strategy equilibrium exists:

$$
\sigma>-\frac{\pi}{1-2 \pi} \equiv \bar{\sigma} \quad \Rightarrow \quad \sigma>-14.21
$$

and

$$
0.483 \leq \frac{-(0.59-0.18 \sigma)(1-\rho)}{(-1.18+0.77 \sigma+0.77 \rho-0.36 \rho \sigma)} \equiv 1-\hat{\pi}
$$

In the unique interior pure-strategy equilibrium, the equilibrium investment levels are given by

$$
\begin{aligned}
& I_{A}^{*}=16450.43\left[\left(\frac{0.517-0.034 \rho}{1-\rho}\right)^{0.41}\left(\frac{0.483+0.034 \sigma}{1-\sigma}\right)^{0.59}\right]^{5.56} \\
& I_{B}^{*}=16450.43\left[\left(\frac{0.517-0.034 \rho}{1-\rho}\right)^{0.59}\left(\frac{0.483+0.034 \sigma}{1-\sigma}\right)^{0.41}\right]^{5.56}
\end{aligned}
$$

Comparing (50) and (53), it is now readily checked that, when (51) and (52) are satisfied, then

- if individuals exhibit competitive preferences $(\sigma \leq \rho \leq 0)$, then there is simultaneous underinvestment in equilibrium $\left(I_{A}^{*}<I_{A}^{s}\right.$ and $\left.I_{B}^{*}<I_{B}^{s}\right)$.

- if individuals exhibit inequity aversion $(\sigma \leq-\rho \leq 0)$, then there are three possible equilibrium outcomes. On the one hand, there may be either simultaneous underinvestment $\left(I_{A}^{*}<I_{A}^{s}\right.$ and $I_{B}^{*}<$ $\left.I_{B}^{s}\right)$ or simultaneous overinvestment $\left(I_{A}^{*}>I_{A}^{s}\right.$ and $\left.I_{B}^{*}>I_{B}^{s}\right)$ in equilibrium. On the other hand, it may also be the case that player $B$ overinvests while player $A$ underinvests in equilibrium $\left(I_{A}^{*}<I_{A}^{s}\right.$ and $\left.I_{B}^{*}>I_{B}^{s}\right)$. 
- if individuals are concerned about social welfare $(\sigma \leq \rho \leq 0)$, then there is simultaneous overinvestment in equilibrium $\left(I_{A}^{*}>I_{A}^{s}\right.$ and $\left.I_{B}^{*}>I_{B}^{s}\right)$.

Consider next the case in which

$$
0.483>\frac{-(0.59-0.18 \sigma)(1-\rho)}{(-1.18+0.77 \sigma+0.77 \rho-0.36 \rho \sigma)} \equiv 1-\hat{\pi}
$$

In this case, there exists a closed set of pure strategy equilibria. In the equilibrium with the highest aggregate investments the players' investment levels are given by

$$
\begin{aligned}
& I_{A}^{\prime \prime}=16450.43\left[\left(\frac{0.517-0.034 \rho}{1-\rho}\right)^{0.41}\left(\frac{0.517-0.034 \rho}{1-\rho}-0.08\right)^{0.59}\right]^{5.56} \\
& I_{B}^{\prime \prime}=16450.43\left[\left(\frac{0.517-0.034 \rho}{1-\rho}-0.08\right)^{0.41}\left(\frac{0.517-0.034 \rho}{1-\rho}\right)^{0.59}\right]^{5.56}
\end{aligned}
$$

In the equilibrium with the lowest aggregate investments the players' investment levels are given by

$$
\begin{aligned}
& I_{A}^{\prime}=16450.43\left[\left(\frac{0.483+0.034 \sigma}{1-\sigma}\right)^{0.59}\left(\frac{0.483+0.034 \sigma}{1-\sigma}+0.08\right)^{0.41}\right]^{5.56} \\
& I_{B}^{\prime}=16450.43\left[\left(\frac{0.483+0.034 \sigma}{1-\sigma}+0.08\right)^{0.59}\left(\frac{0.483+0.034 \sigma}{1-\sigma}\right)^{0.41}\right]^{5.56}
\end{aligned}
$$

Comparing (50) with (55) and (56) respectively, it is now readily checked that, when (54) is satisfied, then

- if individuals exhibit competitive preferences $(\sigma \leq \rho \leq 0)$, then there is simultaneous underinvestment both in the equilibrium with the highest aggregate investment $\left(I_{A}^{\prime \prime}<I_{A}^{s}\right.$ and $\left.I_{B}^{\prime \prime}<I_{B}^{s}\right)$ and in the equilibrium with lowest aggregate investment $\left(I_{A}^{\prime}<I_{A}^{s}\right.$ and $\left.I_{B}^{\prime}<I_{B}^{s}\right)$.

- if individuals exhibit inequity aversion $(\sigma \leq-\rho \leq 0)$, then there is simultaneous overinvestment in the equilibrium with the highest aggregate investment $\left(I_{A}^{\prime \prime}>I_{A}^{s}\right.$ and $\left.I_{B}^{\prime \prime}>I_{B}^{s}\right)$ and simultaneous underinvestment in the equilibrium with lowest aggregate investment $\left(I_{A}^{\prime}<I_{A}^{s}\right.$ and $\left.I_{B}^{\prime}<I_{B}^{s}\right)$.

- if individuals are concerned about social welfare $(\sigma \leq \rho \leq 0)$, then there is simultaneous overinvestment both in the equilibrium with the highest aggregate investment $\left(\bar{I}_{A}>I_{A}^{s}\right.$ and $\left.\bar{I}_{B}>I_{B}^{s}\right)$ and in 
the equilibrium with lowest aggregate investment $\left(\underline{I}_{A}>I_{A}^{s}\right.$ and $\left.\underline{I}_{B}>I_{B}^{s}\right)$.

\section{B Conducting the experiment and instruc- tions}

The experiment was run at the Laboratory of the School of Economics at the University of Jena. Participants were recruited by email with Orsee (Greiner, 2004) and could register for the experiment on the internet. At the beginning of the experiment participants drew balls from an urn to determine their allocation to seats. When seated participants then obtained written instructions in German. In the following we give a translation of the instructions.

After answering control questions on the screen subjects entered the treatment described in the instructions. After completing the treatment they answered a short questionnaire on the screen and where then paid in cash. The experiment was done with the help of z-Tree (Fischbacher (2007)).

\section{Instructions to the experiment}

You are participating in a scientific experiment that is sponsored by the University of Jena and the University of St Andrews in Scotland. The instructions are simple. If you read them carefully then you can-depending on your decision - gain a considerable amount of money which is paid to you at the end of the game.

Your payoff depends on your success in the experiment. During the experiment you gain a certain number of "ECU" (Experimental Currency Units). At the end of the experiment you will be paid in $€$. The conversion rate is $1 €=2000 \mathrm{ECU}$.

When you have questions, then please raise your hand. We will come to you and answer your question. All participants of the experiment receive the same instructions. The information on the screen is, however, only for the individual participant. You are not allowed to have a look at the screen of other participants and you are not allowed to talk to other participants. Please concentrate on the experiment, do not read anything you brought with you, do not try to start any other programs on the computer, do not use your mobile phone. If you do not follow these rules you are excluded from the experiment and you will not be paid.

You will play several rounds. In each round you play together with a randomly selected other player. In each round you and the other player choose each one number. Depending on the numbers you choose you receive a payoff in "ECU" which is determined according to a table. The following example shows only a part of a table, in the experiment you see a complete table. 
number the other player has chosen

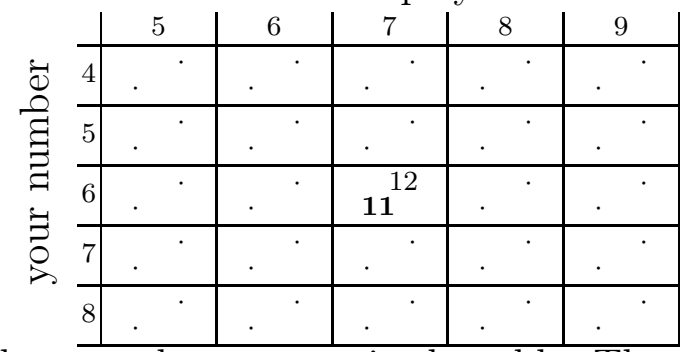

With your number you choose a row in the table. The other player chooses with his number a column in the table. The intersection determines a cell. In the example, when you choose row 6 and the other player column 7 , then your payoff is according to the cell 12 . Your payoff is the boldface number at the bottom left (11), the payoff of the other player is the number at the top right (12). With the help of the table you can determine your payoff for any combination of rows and columns. Your payoff is, hence, determined by the number you have chosen and by the number the other player has chosen.

To help you understand the experiment, please do the following:

- Click a number at the beginning of row as well as a number at the top of a column. The row and the column will be shown in red. The cell at the intersection will be circled.

The row you have chosen corresponds to your number. The column you have chosen corresponds to the number you expect the other player will chose.

- Of course, your expectation of what number the other player might choose neither affects your payoff nor the payoff of the other player. To make a good decision, you can nevertheless think about the possible choices of the other player.

- You can repeat this exercise as often as you wish. You can try different combinations of numbers for yourself and for the other player. When you are satisfied with your choice please push the button $\mathrm{OK}$.

As soon as the other player has completed his decision you see on your screen which number he has chosen and which payoff he has received.

Please write these values in each round into the table that you find on the back of this instruction sheet.

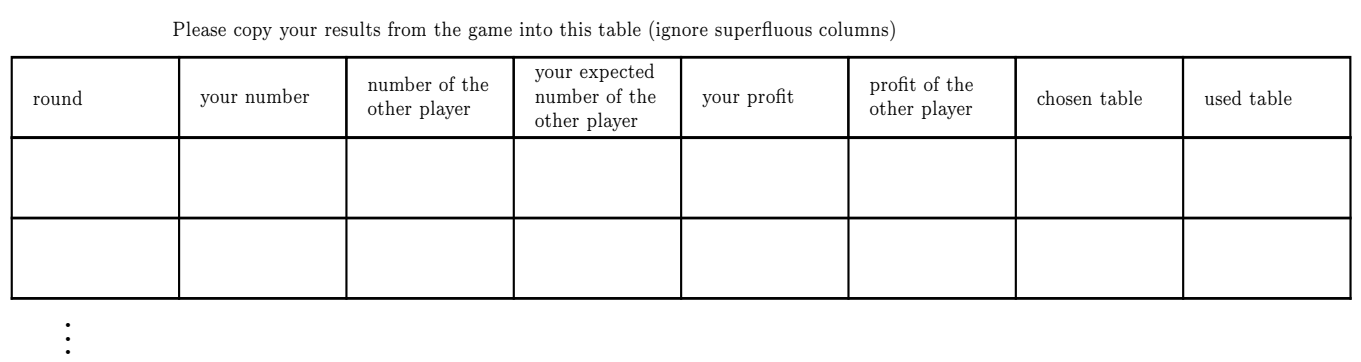



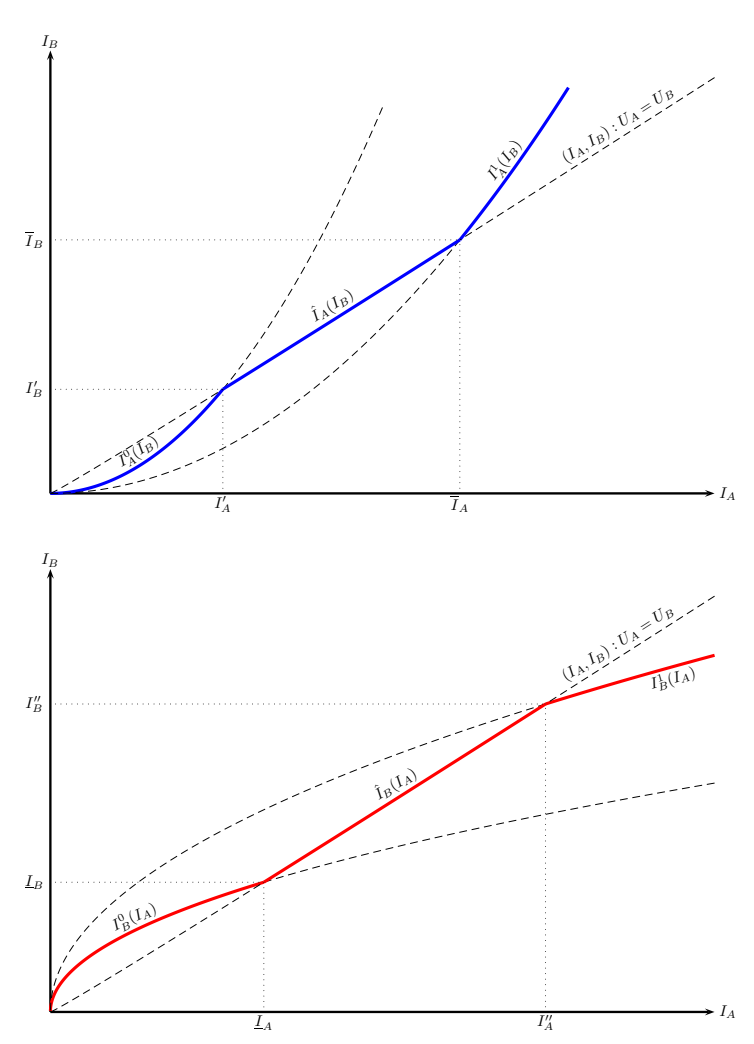

FiguRE 13: Best response functions
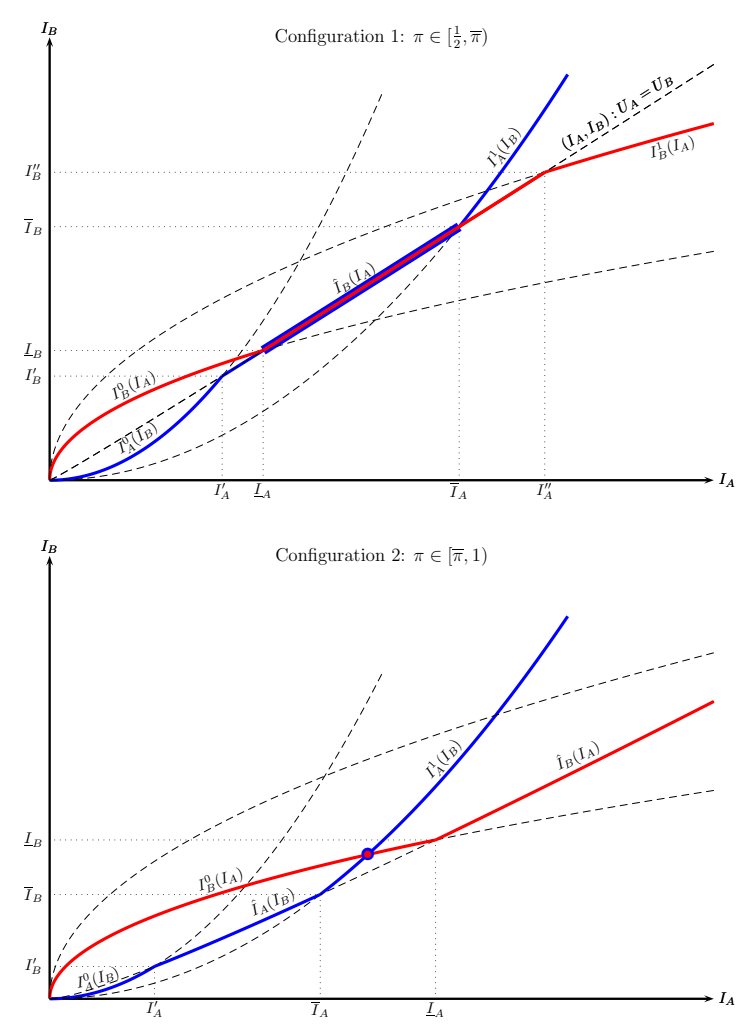

Figure 14: Two possible equilibrium configurations when $\sigma>\hat{\sigma}$

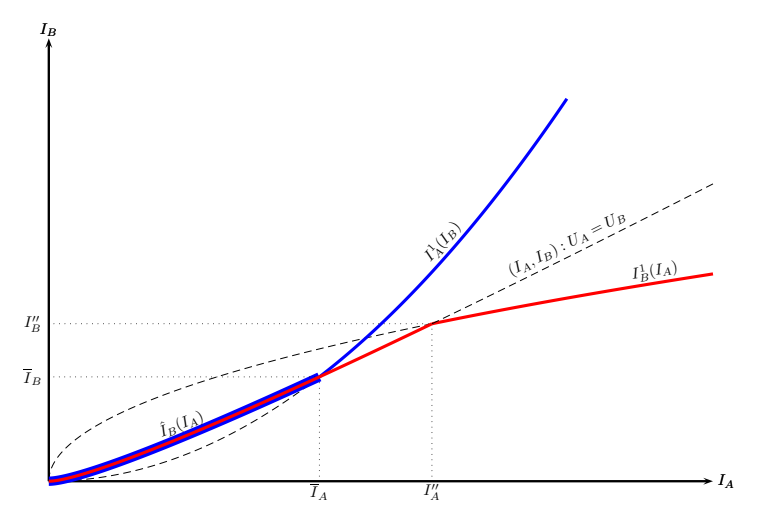

Figure 15: Equilibrium configuration when $\sigma \leq \hat{\sigma}$ 


\section{CESifo Working Paper Series}

for full list see www.cesifo-group.org/wp

(address: Poschingerstr. 5, 81679 Munich, Germany, office@cesifo.de)

2873 Burkhard Heer and Alfred Maußner, Computation of Business-Cycle Models with the Generalized Schur Method, December 2009

2874 Carlo Carraro, Enrica De Cian and Massimo Tavoni, Human Capital Formation and Global Warming Mitigation: Evidence from an Integrated Assessment Model, December 2009

2875 André Grimaud, Gilles Lafforgue and Bertrand Magné, Climate Change Mitigation Options and Directed Technical Change: A Decentralized Equilibrium Analysis, December 2009

2876 Angel de la Fuente, A Mixed Splicing Procedure for Economic Time Series, December 2009

2877 Martin Schlotter, Guido Schwerdt and Ludger Woessmann, Econometric Methods for Causal Evaluation of Education Policies and Practices: A Non-Technical Guide, December 2009

2878 Mathias Dolls, Clemens Fuest and Andreas Peichl, Automatic Stabilizers and Economic Crisis: US vs. Europe, December 2009

2879 Tom Karkinsky and Nadine Riedel, Corporate Taxation and the Choice of Patent Location within Multinational Firms, December 2009

2880 Kai A. Konrad, Florian Morath and Wieland Müller, Taxation and Market Power, December 2009

2881 Marko Koethenbuerger and Michael Stimmelmayr, Corporate Taxation and Corporate Governance, December 2009

2882 Gebhard Kirchgässner, The Lost Popularity Function: Are Unemployment and Inflation no longer Relevant for the Behaviour of Germany Voters?, December 2009

2883 Marianna Belloc and Ugo Pagano, Politics-Business Interaction Paths, December 2009

2884 Wolfgang Buchholz, Richard Cornes and Dirk Rübbelke, Existence and Warr Neutrality for Matching Equilibria in a Public Good Economy: An Aggregative Game Approach, December 2009

2885 Charles A.E. Goodhart, Carolina Osorio and Dimitrios P. Tsomocos, Analysis of Monetary Policy and Financial Stability: A New Paradigm, December 2009

2886 Thomas Aronsson and Erkki Koskela, Outsourcing, Public Input Provision and Policy Cooperation, December 2009 
2887 Andreas Ortmann, "The Way in which an Experiment is Conducted is Unbelievably Important": On the Experimentation Practices of Economists and Psychologists, December 2009

2888 Andreas Irmen, Population Aging and the Direction of Technical Change, December 2009

2889 Wolf-Heimo Grieben and Fuat Şener, Labor Unions, Globalization, and Mercantilism, December 2009

2890 Conny Wunsch, Optimal Use of Labor Market Policies: The Role of Job Search Assistance, December 2009

2891 Claudia Buch, Cathérine Tahmee Koch and Michael Kötter, Margins of International Banking: Is there a Productivity Pecking Order in Banking, too?, December 2009

2892 Shafik Hebous and Alfons J. Weichenrieder, Debt Financing and Sharp Currency Depreciations: Wholly vs. Partially Owned Multinational Affiliates, December 2009

2893 Johannes Binswanger and Daniel Schunk, What is an Adequate Standard of Living during Retirement?, December 2009

2894 Armin Falk and James J. Heckman, Lab Experiments are a Major Source of Knowledge in the Social Sciences, December 2009

2895 Hartmut Egger and Daniel Etzel, The Impact of Trade on Employment, Welfare, and Income Distribution in Unionized General Oligopolistic Equilibrium, December 2009

2896 Julian Rauchdobler, Rupert Sausgruber and Jean-Robert Tyran, Voting on Thresholds for Public Goods: Experimental Evidence, December 2009

2897 Michael McBride and Stergios Skaperdas, Conflict, Settlement, and the Shadow of the Future, December 2009

2898 Ben J. Heijdra and Laurie S. M. Reijnders, Economic Growth and Longevity Risk with Adverse Selection, December 2009

2899 Johannes Becker, Taxation of Foreign Profits with Heterogeneous Multinational Firms, December 2009

2900 Douglas Gale and Piero Gottardi, Illiquidity and Under-Valuation of Firms, December 2009

2901 Donatella Gatti, Christophe Rault and Anne-Gaël Vaubourg, Unemployment and Finance: How do Financial and Labour Market Factors Interact?, December 2009

2902 Arno Riedl, Behavioral and Experimental Economics Can Inform Public Policy: Some Thoughts, December 2009 
2903 Wilhelm K. Kohler and Marcel Smolka, Global Sourcing Decisions and Firm Productivity: Evidence from Spain, December 2009

2904 Marcel Gérard and Fernando M. M. Ruiz, Corporate Taxation and the Impact of Governance, Political and Economic Factors, December 2009

2905 Mikael Priks, The Effect of Surveillance Cameras on Crime: Evidence from the Stockholm Subway, December 2009

2906 Xavier Vives, Asset Auctions, Information, and Liquidity, January 2010

2907 Edwin van der Werf, Unilateral Climate Policy, Asymmetric Backstop Adoption, and Carbon Leakage in a Two-Region Hotelling Model, January 2010

2908 Margarita Katsimi and Vassilis Sarantides, Do Elections Affect the Composition of Fiscal Policy?, January 2010

2909 Rolf Golombek, Mads Greaker and Michael Hoel, Climate Policy without Commitment, January 2010

2910 Sascha O. Becker and Ludger Woessmann, The Effect of Protestantism on Education before the Industrialization: Evidence from 1816 Prussia, January 2010

2911 Michael Berlemann, Marco Oestmann and Marcel Thum, Demographic Change and Bank Profitability. Empirical Evidence from German Savings Banks, January 2010

2912 Øystein Foros, Hans Jarle Kind and Greg Shaffer, Mergers and Partial Ownership, January 2010

2913 Sean Holly, M. Hashem Pesaran and Takashi Yamagata, Spatial and Temporal Diffusion of House Prices in the UK, January 2010

2914 Christian Keuschnigg and Evelyn Ribi, Profit Taxation and Finance Constraints, January 2010

2915 Hendrik Vrijburg and Ruud A. de Mooij, Enhanced Cooperation in an Asymmetric Model of Tax Competition, January 2010

2916 Volker Meier and Martin Werding, Ageing and the Welfare State: Securing Sustainability, January 2010

2917 Thushyanthan Baskaran and Zohal Hessami, Globalization, Redistribution, and the Composition of Public Education Expenditures, January 2010

2918 Angel de la Fuente, Testing, not Modelling, the Impact of Cohesion Support: A Theoretical Framework and some Preliminary Results for the Spanish Regions, January 2010

2919 Bruno S. Frey and Paolo Pamini, World Heritage: Where Are We? An Empirical Analysis, January 2010 
2920 Susanne Ek and Bertil Holmlund, Family Job Search, Wage Bargaining, and Optimal Unemployment Insurance, January 2010

2921 Mariagiovanna Baccara, Allan Collard-Wexler, Leonardo Felli and Leeat Yariv, Gender and Racial Biases: Evidence from Child Adoption, January 2010

2922 Kurt R. Brekke, Roberto Cellini, Luigi Siciliani and Odd Rune Straume, Competition and Quality in Regulated Markets with Sluggish Demand, January 2010

2923 Stefan Bauernschuster, Oliver Falck and Niels Große, Can Competition Spoil Reciprocity? - A Laboratory Experiment, January 2010

2924 Jerome L. Stein, A Critique of the Literature on the US Financial Debt Crisis, January 2010

2925 Erkki Koskela and Jan König, Profit Sharing, Wage Formation and Flexible Outsourcing under Labor Market Imperfection, January 2010

2926 Gabriella Legrenzi and Costas Milas, Spend-and-Tax Adjustments and the Sustainability of the Government's Intertemporal Budget Constraint, January 2010

2927 Piero Gottardi, Jean Marc Tallon and Paolo Ghirardato, Flexible Contracts, January 2010

2928 Gebhard Kirchgässner and Jürgen Wolters, The Role of Monetary Aggregates in the Policy Analysis of the Swiss National Bank, January 2010

2929 J. Trent Alexander, Michael Davern and Betsey Stevenson, Inaccurate Age and Sex Data in the Census PUMS Files: Evidence and Implications, January 2010

2930 Stefan Krasa and Mattias K. Polborn, Competition between Specialized Candidates, January 2010

2931 Yin-Wong Cheung and Xingwang Qian, Capital Flight: China's Experience, January 2010

2932 Thomas Hemmelgarn and Gaetan Nicodeme, The 2008 Financial Crisis and Taxation Policy, January 2010

2933 Marco Faravelli, Oliver Kirchkamp and Helmut Rainer, Social Welfare versus Inequality Concerns in an Incomplete Contract Experiment, January 2010 